\title{
An Excursion into the Intriguing World of Polymeric Tl(I) and Ag(I) Cyanoximates *
}

\section{Nikolay Gerasimchuk}

Department of Chemistry, Temple Hall 456, Missouri State University, 901 South National Avenue, Springfield, MO 65897, USA; E-Mail: NNGerasimchuk@MissouriState.edu; Tel.: +1-417-836-5165

* Dedicated to life of Ingeborg Percoco.

Received: 30 June 2011; in revised form: 16 August 2011 / Accepted: 30 August 2011 / Published: 13 September 2011

\begin{abstract}
The reaction of hot $\left(\sim 95{ }^{\circ} \mathrm{C}\right)$ aqueous solutions of $\mathrm{Tl}_{2} \mathrm{CO}_{3}$ with solid $\mathrm{HL}$ $(\mathrm{HL}=\mathrm{NC}-\mathrm{C}(=\mathrm{N}-\mathrm{OH})-\mathrm{R}$ is a cyanoxime, and $\mathrm{R}$ is an electron-withdrawing group; 37 ligands are known up-to-date) leads to crystalline yellow/orange TIL. Similarly, the reaction between $\mathrm{AgNO}_{3}$ and $\mathrm{ML}\left(\mathrm{M}=\mathrm{K}^{+}, \mathrm{Na}^{+} ; \mathrm{L}=\right.$ anion of the monodeprotonated cyanoxime $)$ this time at room temperature in mixed ethanol/aqueous solutions leads to sparingly soluble, colored AgL in high-yield. All synthesized monovalent $\mathrm{Tl}$ and Ag complexes were characterized using a variety of spectroscopic methods and X-ray analysis, which revealed the formation of primarily $2 \mathrm{D}$ coordination polymers of different complexity. In all cases cyanoxime mono-anions act as bridging ligands. Thallium(I) cyanoximates adopt in most cases a double-stranded motif that is originated from centrosymmetric (TIL) 2 dimers in which two $\mathrm{Tl}_{2} \mathrm{O}_{2}$ rhombs are fused into infinite "ladder-type" structure. There are very short (3.65-3.85 $\AA$ ) intermetallic distances in (TlL) $)_{n}$, which are close to that (3.46 $\AA$ ) in metallic thallium. This opens the possibility for the electrochemical or chemical generation of mixed valence $\mathrm{Tl}(\mathrm{I}) / \mathrm{Tl}(\mathrm{III})$ polymers that may exhibit electrical conductivity. Synthesized silver(I) compounds demonstrate a very significant (for multiple years!) stability towards visible light. There are three areas of potential practical applications of these unusual complexes: (1) battery-less detectors of UV-radiation, (2) non electrical sensors for gases of industrial importance, (3) antimicrobial additives to light-curable acrylate polymeric glues, fillers and adhesives used during introduction of indwelling medical devices. Chemical, structural, technological and biological aspects of application of $\mathrm{Tl}(\mathrm{I})$ and $\mathrm{Ag}(\mathrm{I})$ cyanoximes-based coordination polymers are reviewed.
\end{abstract}


Keywords: cyanoximes; coordination polymers of $\mathrm{Tl}(\mathrm{I})$ and $\mathrm{Ag}(\mathrm{I})$; X-ray analysis; UV-radiation; sensors

\section{Introduction}

Coordination polymers are different from conventional organic polymers because of at least two reasons. First of all, there are no pure covalent bonds between the monomeric unit of the former, but rather donor-acceptor type polar bonds instead. Secondly, coordination polymers form elaborate and frequently very complex 2D and 3D repetitive structures as opposed to a variety of different chains of conventional organic polymers. This fact leads to the higher density of coordination polymers and their much higher thermal stability, which is an important factor for their practical applications. These are, in particular, extended solids as magnetic materials [1] (and the references therein), 1D electrical conductors for molecular electronics [2] (and the references therein), and gas storage [3] (and the references therein).

In this work we summarize up-to-date results of our studies of coordination polymers based on cyanoximes - a new class of small organic molecules that exhibit properties of excellent anionic ligands that bind a variety of metal ions [4-9]. The relationship between different subclasses of oximes and their precursors is shown in Figure 1. Within the last decade we developed three routes of the Meyer reaction [10] that afford cyanoximes in yields above $60 \%$ (Figure 2), with the route 3 using gaseous methylnitrite being the most successful in preparation of different aryl-ligands [11] (Electronic Supporting Information: ESI 1). Thus, using a large variety of readily available substituted acetonitriles, 37 different cyanoximes were obtained and characterized by means of different spectroscopic techniques and the X-ray analysis. The cyanoximes are weak acids and quite comparable in strength to carboxylic acids: their pKa values range from 4.2 to 6.2 [12,13]. However, they are much more acidic ligands than conventional monoximes and dioximes with typical $\mathrm{pKa}$ values for the latter around 9-10 [14,15].

Figure 1. The relationship between different classes of oximes and their precursors.<smiles>[R]C=O</smiles><smiles>[R]C([R])=O</smiles><smiles>[R]C[N+]#N</smiles>
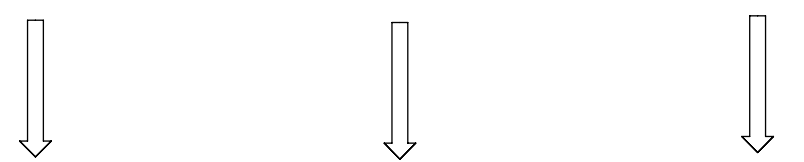

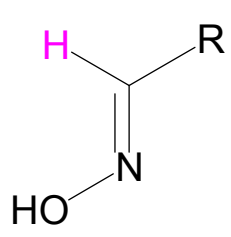

Aldoximes

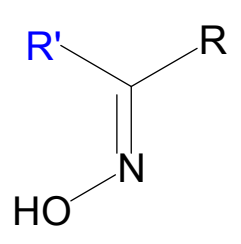

ketoximes

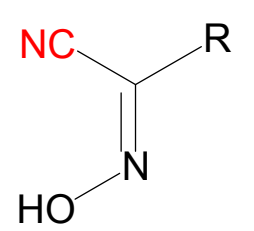

cyanoximes 
Figure 2. Three developed high-yield routes to cyanoximes.

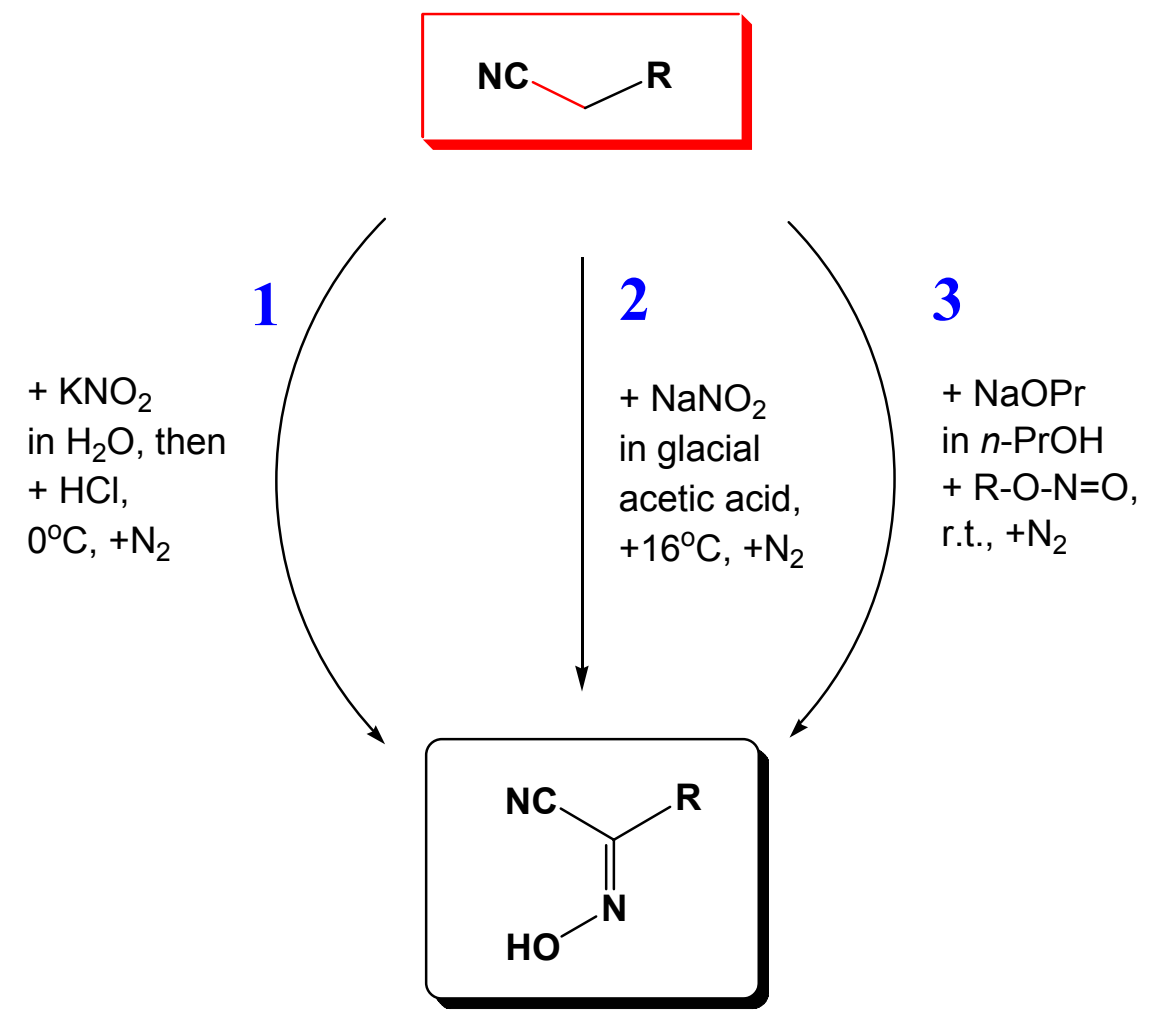

A complete list of these molecules is presented in Figure 3 with their commonly used abbreviations, while their rich stereochemistry is explained in ESI 2.

The cyanoximes represent a new class of ampolydentate (not ambidentate) organic ligands because their binding ability is not limited to only two donor centers such as those in traditional $\mathrm{NO}_{2}^{-}, \mathrm{NCO}^{-}$, $\mathrm{NCS}^{-}$, and $\mathrm{NCSe}^{-}$ions that show linkage isomerism [16-18]. Thus, even in the case of one of the simplest cyanoxime anions, $\mathrm{ACO}^{-}$, there are possible several binding modes with many of them experimentally confirmed by the X-ray crystallography (Figure 4). In recent years we were specifically interested in synthesis and subsequent investigations of rather unique and interesting complexes of cyanoximes based on monovalent silver and thallium. These compounds turned out to be coordination polymers of different complexity in which anionic cyanoximes act as bridging ligands sometimes showing unusual binding modes. Silver(I) polymeric cyanoximates showed quite remarkable stability towards visible light, which can be utilized in several practical applications [19-21], while polymeric thallium(I) cyanoximates are attractive building blocks and templates [22] for the preparation of mixed valence $\mathrm{Tl}(\mathrm{I}) / \mathrm{Tl}(\mathrm{III})$ systems that may exhibit electrical conductivity. This is an important property in design of molecular wires and in other molecular electronics applications [23]. 
Figure 3. Currently known and studied cyanoximes. A red asterisk indicates compounds for which crystal structures were determined.

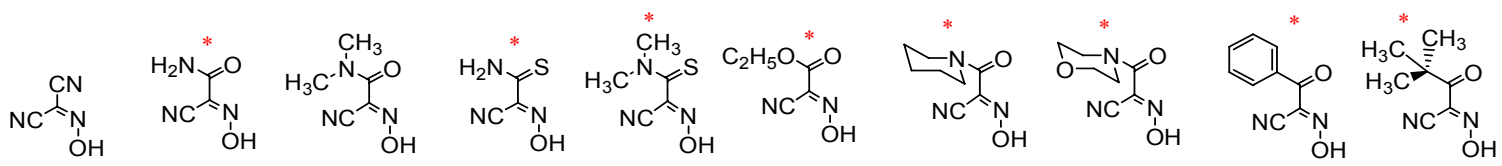

$$
\begin{aligned}
& \begin{array}{llllllllll}
1 & 2 & 3 & 4 & 5 & 6 & 7 & 8 & 9 & 10
\end{array} \\
& \text { CCO HACO HDCO HTCO HTDCO HECO HPiPCO HMCO HBCO HPiCO } \\
& \text { Amido- / ester- and keto- cyanoximes }
\end{aligned}
$$

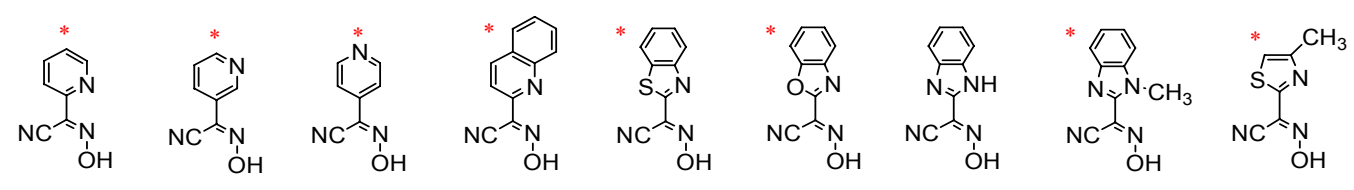

$$
\begin{aligned}
& \begin{array}{lllllllll}
11 & 12 & 13 & 14 & 15 & 16 & 17 & 18 & 19
\end{array} \\
& \text { H2PCO H3PCO H4PCO HQCO HBTCO HBOCO HBIHCO HBIMCO HTLCO } \\
& \text { Heterocyclic cyanoximes }
\end{aligned}
$$<smiles>N#Cc1ccccc1F</smiles><smiles>N#Cc1ccccc1Cl</smiles><smiles>N#CC(NO)c1ccccc1Br</smiles><smiles>N#Cc1cccc(F)c1</smiles>

22
$2 B r-P h C O$<smiles>N#Cc1cccc(Cl)c1</smiles>

24<smiles>N#CC(NO)c1cccc(Br)c1</smiles>

25

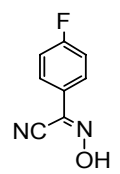<smiles>N#Cc1ccc(Cl)cc1NO</smiles>

27

H4F-PhCO H4Cl-PhCO H4Br-PhCO<smiles>N#CC(NO)C(F)c1ccccc1F</smiles>

29<smiles>N#CC(=NO)c1c(F)cccc1Cl</smiles>

30

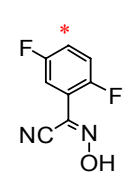

31<smiles>N#CC(NO)c1ccc(F)cc1F</smiles>

32<smiles>N#CC(NO)c1ccc(Cl)cc1Cl</smiles>

33<smiles>N#CC(=NO)c1ccc(Br)cc1</smiles>

28

H2,6-diF-PhCO

H2F6Cl-PhCO

H3,5-diF-PhCO

H2,4-diF-PhCO

H2,4-diCl-PhCO<smiles>N#CC(NO)c1c(Cl)cccc1Cl</smiles>

$\mathrm{D}$

Disubstituted arylcyanoximes

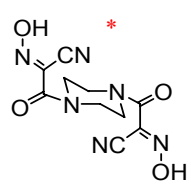

35

H2BiPiPCO<smiles>N#CC(=NO)c1cccc(C(C#N)C#N)c1</smiles>

36

1,3-diox-Ph<smiles>N#CC(NO)c1ccc(C(C#N)NO)cc1</smiles>

37

Bis-cyanoximes

1,4-diox-Ph 
Figure 4. Some of the most probable binding modes of the acetamide-cyanoxime anion, $\mathrm{ACO}^{-}$. Framed structures with cited metals were confirmed by the X-ray analysis.
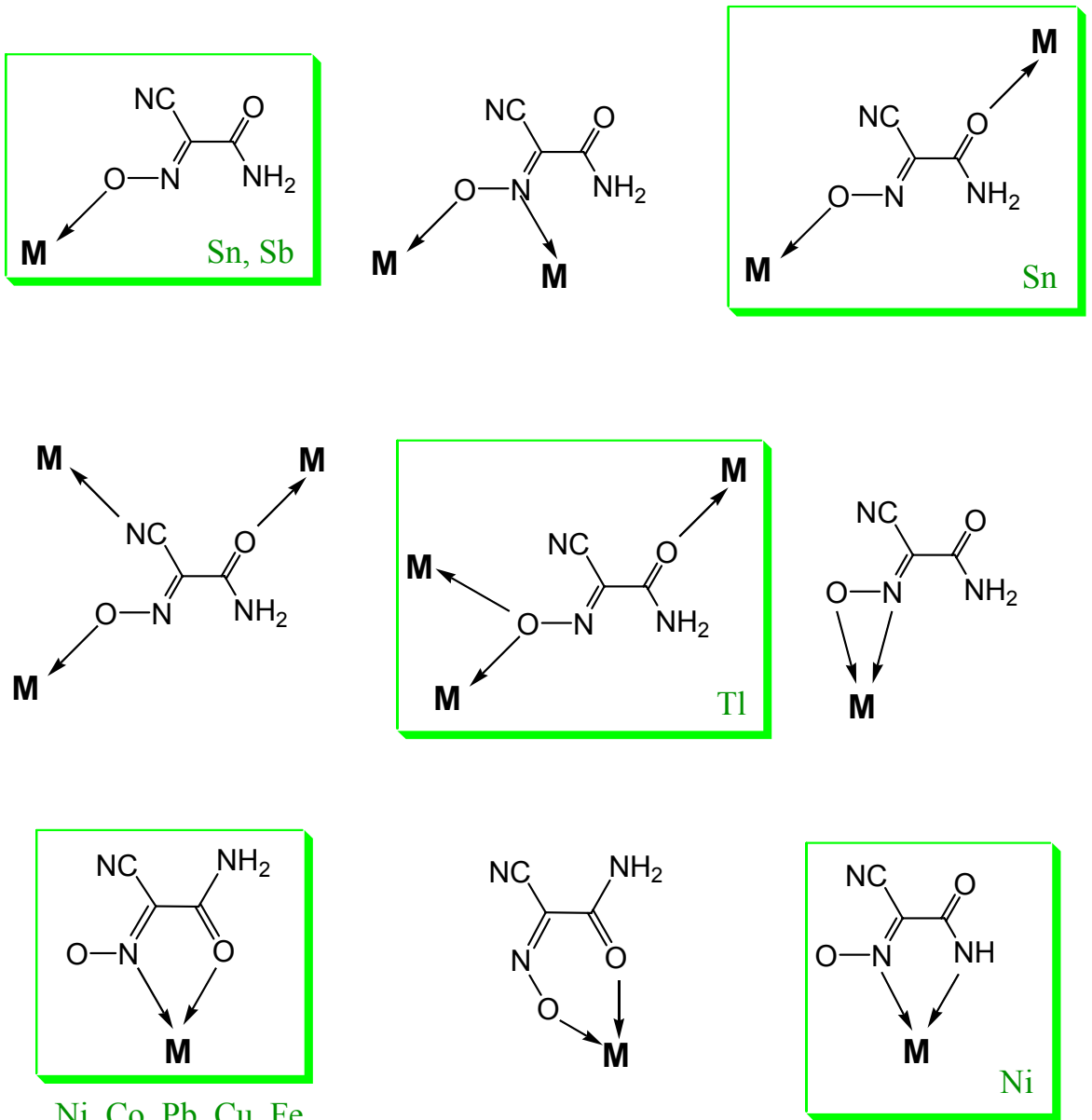

$\mathrm{Ni}, \mathrm{Co}, \mathrm{Pb}, \mathrm{Cu}, \mathrm{Fe}$

\section{Some Aspects of the Chemistries of $\mathrm{Tl}(\mathrm{I})$ and $\mathrm{Ag}(\mathrm{I})$}

Monovalent thallium and silver have many interesting common properties. Thus, they both readily form black basic oxides $\mathrm{M}_{2} \mathrm{O}$, black sparingly soluble sulfides $\mathrm{M}_{2} \mathrm{~S}$, halogenides $\mathrm{MHal}(\mathrm{Hal}=\mathrm{Cl}, \mathrm{Br}$, I), phosphates $\mathrm{M}_{3} \mathrm{PO}_{4}$, and perchlorates $\mathrm{MClO}_{4}$. The affinity of halogens to the $\mathrm{Tl}(\mathrm{I})$ cation is significantly greater than that for $\mathrm{Ag}(\mathrm{I})$ as evidenced from values of their MHal bond formation enthalpies (ESI 3). This trend is widely used in synthetic organic, organometallic and inorganic chemistry in metathesis reactions when the use of $\operatorname{Ag}(\mathrm{I})$ salts, that are unstable around heat and light, is prohibitive. Further, black $\mathrm{Tl}_{2} \mathrm{O}$ is thermally very stable as opposed to $\mathrm{Ag}_{2} \mathrm{O}$ which spontaneously decomposes to metallic $\mathrm{Ag}$ and oxygen at room temperature, and quickly at elevated temperatures. Contrary to $\mathrm{AgOH}$, yellow $\mathrm{TlOH}$ is a stable strong base, while $\mathrm{Tl}_{2} \mathrm{CO}_{3}, \mathrm{Tl}_{2} \mathrm{SO}_{4}$ are water soluble. This makes thallium(I) chemically resembling potassium, and that is successfully utilized, for example, in medical practice in studies by the ${ }^{205} \mathrm{Tl}$ NMR method monovalent ions transport in vivo and their binding to biological molecules [24] (and references therein). In a sense, thallium does not possess specific and distinctive chemical properties and always "hides its face behind somebody else" [25]. Thallium(I) is an oxophylic, soft acid metal cation according to the HSAB principle [26] with a very low absolute hardness parameter $\eta=2.24 \mathrm{eV}$ (Table 1$)$. 
Table 1. Physical and chemical data for thallium, silver and their monovalent cations.

\begin{tabular}{lcc}
\hline \multicolumn{1}{c}{ Parameter } & Tl & Ag \\
\hline Electron affinity, $\mathrm{kJ} / \mathrm{M}$ & 19.2 & 125.5 \\
M---M bond energy, $\mathrm{kJ} / \mathrm{M}$ & 64.4 & 160.3 \\
Absolute hardness, $\mathrm{n}, \mathrm{eV}$ & 2.24 & 6.96 \\
$\mathrm{M}^{+}$covalent radius, $\AA$ & 1.45 & 1.45 \\
$\mathrm{M}^{+}$ionic radius, $\AA$ & 1.64 & 1.14 \\
Sum of M-O covalent radii $^{1}, \AA$ & 2.11 & 2.11 \\
Sum of M-O ionic radii ${ }^{2}, \AA$ & 2.88 & 2.38 \\
Sum of M-N covalent radii ${ }^{3}, \AA$ & 2.16 & 2.16 \\
Sum of M-N ionic radii ${ }^{4}, \AA$ & 2.96 & 2.46 \\
M---M distance in pure metal, $\AA$ & 3.456 & 4.086 \\
Covalent metal-metal bond, $\AA$ & 3.408 & 2.889 \\
Most relevant redox potentials, ${ }^{5} \mathrm{~V}^{0}:$ & $\mathrm{Tl}^{+} \rightarrow \mathrm{Tl}^{0}=-0.336$ & $\mathrm{Ag}^{+} \rightarrow \mathrm{Ag}^{0}=-0.799$ \\
& $\mathrm{Tl}^{+} \rightarrow \mathrm{Tl}^{3+}=1.25$ & $\mathrm{Ag}^{+} \rightarrow \mathrm{Ag}^{2+}=1.980$ \\
\hline
\end{tabular}

All data from reference [23]: ${ }^{1}$ - using oxygen covalent radius value of $0.66 \AA_{;}{ }^{2}$ - for oxygen ionic radius value of $1.24 \AA \dot{ }^{3}$ - for nitrogen covalent radius of $0.71 \AA{ }^{4}$ - for nitrogen ionic radius of $1.32 \AA{ }^{5}{ }^{5}$ - against NHE.

Thallium has trivalent state which is separated from the monovalent by rather high redox potential, with the former being a strong oxidizer (Table 1). An electron affinity of Tl(I) is $\sim 6$ times less than that for $\mathrm{Ag}(\mathrm{I})$ (Table 1), which makes thallium complexes very stable towards reduction as opposed to silver compounds. As a main group III element, monovalent thallium has a $6 \mathrm{~s}^{2}$ lone pair, which always defines its stereochemistry and significantly distorts the shape of the Tl(I) coordination polyhedron and, respectively, its compounds. The latter, coupled with a fairly large size of Tl(I) ion (1.64 $\AA$ for six-coordinate environment [27]) and its polarizability leads to an interesting general trend in the structural chemistry of this metal: there are typically 2-3 short distances between the metal center and oxygen atoms in complexes, and 2-3 much longer electrostatic contacts with other donor atoms. This quite unusual for structural coordination chemistry distribution of bond lengths around the large in size metal center leads to the adoption of odd shapes of coordination polyhedra of Tl(I) in its complexes. This phenomenon will be shown later.

Contrary to $\mathrm{Tl}(\mathrm{I})$, silver(I) is a transition metal ion with $[\mathrm{Kr}] 4 \mathrm{~d}^{10} 5 \mathrm{~S}^{0}$ ground state configuration, $1.14 \AA$ value of its ionic radius [27] and $\mathrm{Ag}(\mathrm{I})$ stereochemistry is defined by these factors. Thus, in silver(I) complexes the most typical coordination numbers are 2 and 3 with the adoption of the linear, or trigonal planar shapes due to the bonding electron pairs repulsion as predicted by VSEPR theory [28]. The $\operatorname{Ag}(\mathrm{I})$ is a pronounced nitrophylic soft acid metal cation [29] with its absolute hardness parameter of $6.96 \mathrm{eV}$, which is significantly greater than that for Tl(I) (Table 1). In its numerous coordination compounds silver(I) prefers nitrogen atoms to oxygen atoms in its environment as evident from their crystal structures. Relevant to the structural chemistry is a comparison of values for M---M bond formation energies for both metals (Table 1). Silver-silver bond energy is almost three times greater than that for $\mathrm{Tl}-\mathrm{Tl}$ bond and provides a good explanation for observed very short intermetallic separations in many Ag-complexes that is frequently called "argentophilicity" [30] (and references therein), which also defines the shapes of their coordination polyhedrons. 


\section{Coordination Polymers of Tl(I) with Cyanoximes}

\subsection{Synthesis, Characterization and Properties}

The majority of monovalent thallium oximate complexes can be prepared as shown in Scheme 1 with the carbonate route 3 being the most effective in getting crystalline samples for different studies. Thus, to a hot $\left(\sim 95{ }^{\circ} \mathrm{C}\right)$ aqueous solution of $\mathrm{Tl}_{2} \mathrm{CO}_{3}$ small portions of the equivalent amount of solid $\mathrm{HL}$ are added within $\sim 3-5 \mathrm{~min}$. When all $\mathrm{CO}_{2}$ is ceased, a yellow solution of TlL is hot-filtered into a large mouth test tube immersed in the $5 \mathrm{~L}$ Dewar flask filled with boiling water, or preheated digital thermostat (ESI 4). Slow cooling within 4-5 days affords TIL crystals that are suitable for the X-ray analysis and other studies, which were filtered off and dried in a dessicator charged with $\mathrm{CaCl}_{2}$. Some physical-chemical parameters and crystal data for all $\mathrm{Tl}(\mathrm{I})$ cyanoximates that were obtained and studied up-to-date are presented in Table 2.

Safety note: Although we have not encountered any problems during many years of laboratory work and handling, special care should be taken during work with thallium compounds because of their high toxicity [31]: $600 \mathrm{mg}$ intake represents a lethal dose [32]. Both Tl(I) carbonate and cyanoximates are water-soluble compounds, and that emphasizes the absolute necessity for wearing protective gloves at all times when working with these compounds. However, no respiratory tract covers are required since Tl(I) compounds are ionic and not volatile.

Scheme 1. Routes to polymeric Tl(I) cyanoximates.

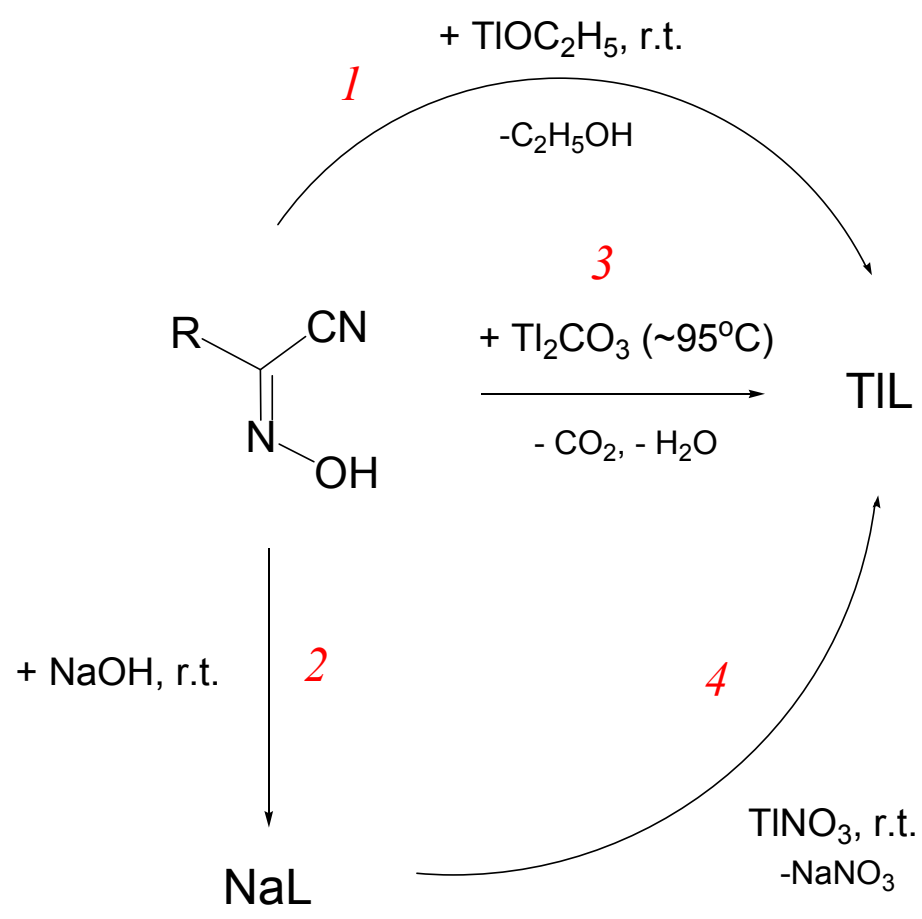


Table 2. Some chemical-physical parameters and crystal structures data for known up to date polymeric Tl(I) cyanoximates.

\begin{tabular}{|c|c|c|c|c|c|c|c|c|c|}
\hline \multirow[b]{2}{*}{ TIL } & \multirow[b]{2}{*}{ Color } & \multirow{2}{*}{$\begin{array}{c}\text { m.p. } \\
\text { (dec.p.) } \\
{ }^{\circ} \mathbf{C} \\
\end{array}$} & \multicolumn{4}{|c|}{ Crystal data } & \multirow[b]{2}{*}{ Structure type } & \multirow[b]{2}{*}{$\begin{array}{l}\text { Tl: } \\
\text { C.N. }\end{array}$} & \multirow[b]{2}{*}{ Ref. } \\
\hline & & & $\begin{array}{c}\text { crystal system, } \\
\text { group }\end{array}$ & $\begin{array}{c}\text { unit cell dimensions, } \\
\AA,\left[^{\circ}\right]\end{array}$ & $\begin{array}{c}\mathrm{V}, \AA^{3} \\
(Z)\end{array}$ & $\begin{array}{c}\text { Density } \\
\text { g/mL }\end{array}$ & & & \\
\hline $\mathrm{Tl}(\mathrm{CCO})$ & Orange & $205-9$ & $\begin{array}{l}\text { Monoclinic, } \\
C 2 / c\end{array}$ & $\begin{array}{l}a=15.5346 ; \beta=129.69 \\
b=8.2402 ; \\
c=10.5347\end{array}$ & $\begin{array}{l}1,037.7 \\
(8)\end{array}$ & 3.82 & Complex 3D network & 7 & {$[19]$} \\
\hline Tl(ACO & Orange & $\begin{array}{l}>230 \\
(\mathrm{dec})\end{array}$ & $\begin{array}{l}\text { Orthorhombic, } \\
\text { Pna } 2_{1}\end{array}$ & $\begin{array}{l}\mathrm{a}=10.983 \\
\mathrm{~b}=13.270 \\
\mathrm{c}=4.034\end{array}$ & $\begin{array}{c}587.9 \\
(4)\end{array}$ & 3.58 & $\begin{array}{c}\text { 3D framework based on } \\
\text { double-stranded } \mathrm{Tl}_{2} \mathrm{O}_{2} \text { sheets } \\
\text { joined by } \mathrm{H} \text {-bonds }\end{array}$ & 5 & {$[35]$} \\
\hline $\mathrm{Tl}(\mathrm{TDCO})$ & Red & $\begin{array}{l}\sim 165 \\
(\mathrm{dec})\end{array}$ & $\begin{array}{l}\text { Orthorhombic, } \\
\quad P 2_{1} 2_{1} 2_{1}\end{array}$ & $\begin{array}{l}\mathrm{a}=25.800 \\
\mathrm{~b}=7.916 \\
\mathrm{c}=4.046\end{array}$ & $\begin{array}{l}826.3 \\
(4)\end{array}$ & 2.90 & $\begin{array}{l}\text { 2D layered structure: } \mathrm{Tl}_{2} \mathrm{~S}_{2} \\
\text { rhombs are joint via } \mathrm{O} \text { atoms of } \\
\text { the oxime groups }\end{array}$ & 6 & {$[68]$} \\
\hline $\mathrm{Tl}(4 \mathrm{PCO})$ & Orange & $\begin{array}{l}\sim 258 \\
(\mathrm{dec})\end{array}$ & $\begin{array}{l}\text { Monoclinic, } \\
\qquad P 2_{1} / n\end{array}$ & $\begin{array}{l}a=3.8990 ; \beta=93.54 \\
b=12.3800 \\
c=16.7563\end{array}$ & $\begin{array}{l}807.28 \\
(4)\end{array}$ & 2.88 & $\begin{array}{l}\text { 2D polymer, double- stranded; } \\
\mathrm{Tl}_{2} \mathrm{O}_{2} \text { rhombs from }[\mathrm{TlL}]_{2} \\
\text { centrosymmetric dimers }\end{array}$ & 5 & {$[70]$} \\
\hline
\end{tabular}


Table 2. Cont.

\begin{tabular}{|c|c|c|c|c|c|c|c|c|c|}
\hline \multirow[b]{2}{*}{ TIL } & \multirow[b]{2}{*}{ Color } & \multirow{2}{*}{$\begin{array}{l}\text { m.p. } \\
\text { (dec.p.) } \\
{ }^{\circ} \mathrm{C}\end{array}$} & \multicolumn{4}{|c|}{ Crystal data } & \multirow[b]{2}{*}{ Structure type } & \multirow[b]{2}{*}{$\begin{array}{l}\text { Tl: } \\
\text { C.N. }\end{array}$} & \multirow[b]{2}{*}{ Ref. } \\
\hline & & & $\begin{array}{c}\text { crystal system, } \\
\text { group }\end{array}$ & $\begin{array}{c}\text { unit cell dimensions, } \\
\AA,\left[^{\circ}\right]\end{array}$ & $\begin{array}{l}\mathbf{V}, \AA^{3} \\
(Z)\end{array}$ & $\begin{array}{l}\text { Density } \\
\text { g/mL }\end{array}$ & & & \\
\hline $\mathrm{Tl}(\mathrm{PiCO})$ & Yellow & $\begin{array}{l}\sim 170 \\
(\mathrm{dec})\end{array}$ & $\begin{array}{c}\text { Triclinic } \\
P-1\end{array}$ & $\begin{array}{l}a=9.914 ; \alpha=82.73 \\
b=11.540 ; \beta=80.80 \\
c=13.281 ; \gamma=79.04\end{array}$ & $\begin{array}{c}1,465.3 \\
(1)\end{array}$ & 2.431 & $\begin{array}{l}\text { Very complex 3D polymer with } \\
\text { three different binding modes of } \\
\text { the anion to } \mathrm{Tl}(\mathrm{I})\end{array}$ & 4 & [71] \\
\hline $\mathrm{Tl}(\mathrm{BTCO})$ & Brown & $\begin{array}{l}\sim 160 \\
\text { (dec) }\end{array}$ & $\begin{array}{l}\text { Monoclinic, } \\
\quad P 2_{1} / c\end{array}$ & $\begin{array}{l}a=14.8621 ; \beta=90.15 \\
b=4.4277 \\
c=15.0453\end{array}$ & $\begin{array}{l}990.1 \\
(2)\end{array}$ & 2.728 & $\begin{array}{l}\text { 2D polymer, double- stranded; } \\
\mathrm{Tl}_{2} \mathrm{O}_{2} \text { rhombs from }[\mathrm{TlL}]_{2} \\
\text { centrosymmetric dimers }\end{array}$ & 3 & {$[12]$} \\
\hline $\mathrm{Tl}(\mathrm{PhCO})$ & $\begin{array}{l}\text { Pale- } \\
\text { yellow }\end{array}$ & $\begin{array}{c}270 \\
(\mathrm{dec})\end{array}$ & $\begin{array}{c}\text { Orthorhombic, } \\
\text { Pbca }\end{array}$ & $\begin{array}{l}a=15.2262 \\
b=6.9272 \\
c=32.4520\end{array}$ & $\begin{array}{c}3,222.3 \\
(16)\end{array}$ & 2.713 & $\begin{array}{l}\text { 2D polymer, double-stranded } \\
\mathrm{Tl}_{2} \mathrm{O}_{2} \text { blocks from }[\mathrm{TlL}]_{2} \text { non- } \\
\text { centrosymmetric dimers }\end{array}$ & 3 & {$[72]$} \\
\hline $\mathrm{Tl}(2 \mathrm{Cl}-\mathrm{PhCO})$ & $\begin{array}{l}\text { Lemon- } \\
\text { yellow }\end{array}$ & $\begin{array}{l}>280 \\
(\mathrm{dec})\end{array}$ & $\begin{array}{l}\text { Monoclinic, } \\
\qquad 2_{1} / n\end{array}$ & $\begin{array}{l}a=3.8382 ; \beta=92.45 \\
b=11.0065 \\
c=20.901\end{array}$ & $\begin{array}{l}882.2 \\
(4)\end{array}$ & 2.891 & $\begin{array}{l}\text { 2D polymer, double- stranded; } \\
\mathrm{Tl}_{2} \mathrm{O}_{2} \text { rhombs from }[\mathrm{TlL}]_{2} \\
\text { centrosymmetric dimers }\end{array}$ & 3 & {$[22]$} \\
\hline $\mathrm{Tl}(4 \mathrm{Br}-\mathrm{PhCO})$ & Orange & $\begin{array}{l}\sim 255 \\
(\mathrm{dec})\end{array}$ & $\begin{array}{l}\text { Monoclinic, } \\
\qquad P 2_{1} / n\end{array}$ & $\begin{array}{l}\mathrm{a}=13.1112 ; \beta=92.14 \\
\mathrm{~b}=4.0577 \\
\mathrm{c}=17.0940\end{array}$ & $\begin{array}{l}908.8 \\
(4)\end{array}$ & 3.131 & $\begin{array}{c}\text { 2D polymer, double- stranded; } \\
\mathrm{Tl}_{2} \mathrm{O}_{2} \text { rhombs from }[\mathrm{TlL}]_{2} \\
\text { centrosymmetric dimers }\end{array}$ & 3 & {$[22]$} \\
\hline Tl(TLCO) & Orange & $\begin{array}{c}220 \\
(\operatorname{dec})\end{array}$ & $\begin{array}{l}\text { Monoclinic, } \\
\qquad P 2_{1} / n\end{array}$ & $\begin{array}{l}a=3.837 ; \beta=94.99 \\
b=29.684 \\
c=14.805\end{array}$ & $\begin{array}{l}1,679.7 \\
(2)\end{array}$ & 2.932 & $\begin{array}{l}\text { tetramer, contains both chelate, } \\
\text { and bridging nitroso- groups, } \\
\text { which are disordered (syn- and } \\
\text { anti- isomers !) }\end{array}$ & 4 & {$[73]$} \\
\hline
\end{tabular}


Practically all TIL can be solubilized in water, forming dilute solutions upon application of the ultrasound and moderate heating to $\sim 65^{\circ} \mathrm{C}$, but the attainable concentration of complexes depends on the hydrophilicity/hydrophobicity of the cyanoxime ligand. All TIL complexes that are soluble in water lose their solid state structures in solutions and form 1:1 type electrolyte which evidences their ionic character [19]. Synthesized TIL are much better soluble in strong donor solvents such as DMSO, DMF, pyridine and 2-picoline, and also form electrolytic solutions. Both aqueous and non-aqueous solutions can be used for the preparation of thin films of the TIL on a glass or quartz surface using either dipping or spin-coating methods.

UV-visible spectra of the yellow-orange TIL show in all cases $n \rightarrow \pi^{*}$ transition in the cyanoxime ligand, in the range of 390-450 $\mathrm{nm}$ [33]. With the exception of only two complexes-Tl(BIHCO) [12] and $\mathrm{Tl}(\mathrm{CCO})$ [19] —all other investigated TlL complexes do not exhibit appreciable emission properties.

\subsection{Crystal Structures}

All ORTEP diagrams shown in this contribution are drawn at a 50\% thermal ellipsoids probability level; other figures were drawn using the XP and Mercury software packages.

Fourteen crystal structures of different TIL have been determined, and crystal data is summarized in Table 2. Without an exception all complexes represent dense coordination polymers in which anions always act as bridging ligands. The experimentally observed binding modes in thallium(I) cyanoximates are shown in Scheme 2. However, if there is an appropriate chance for the chelate ring formation with participation of other donor atoms $(\mathrm{O}, \mathrm{N}$ or $\mathrm{S})$, then this binding mode is present in addition to the bridging function of anions (Scheme $2(\mathrm{~A})$ ) as can be seen in the structures of $\mathrm{Tl}(2 \mathrm{PCO}), \mathrm{Tl}(\mathrm{PiCO})$ and Tl(TDCO). The most abundant binding mode so far ( 6 structures) was found to be the one with the ligand in the oxime form and initiation of the $\mu^{3}$-oxo-bridge (Scheme 2(B); Table 2), with two closely related structures of $\mathrm{Tl}(3 \mathrm{PCO})$ and $\mathrm{Tl}(4 \mathrm{PCO})$ depicted on Scheme 2(E,F) respectively. In the latter complex the anion also shows a rare side-on coordination that was previously observed only for sterically constrained monomeric $\mathrm{Tl}(\mathrm{I})$ cyanoximates containing macrocyclic ligands [34]. An extensive bridging exclusively via oxygen atoms was detected in only one complex-T1(ACO) [35] (Scheme 2(D)). The only one example of reliably assigned monodentate coordination of the cyano-group to the metal center was observed in another monomeric Tl(I) macrocyclic complex with $\mathrm{H}(\mathrm{BTCO})_{2}{ }^{-}$anion [36], while formation of the coordination polymer with coordinated $\mathrm{CN}$-group was recently reported in the structure of $\mathrm{Tl}(\mathrm{CCO})$ [19] as sketched in Scheme 2(D).

Central metal ions in $\mathrm{Tl}(\mathrm{I})$ coordination polymers that have been synthesized and studied so far exhibit a variety of coordination numbers, and shapes of the coordination polyhedra are presented in detail in the ESI 5-10, but are out of the scope of this presentation. The $6 \mathrm{~s}^{2}$ lone pair is stereoactive in all cases, and its location can be visualized from figures provided there. Hence, all building blocks-individual coordination polyhedral - in these complexes are significantly distorted. The organizations of 2D (in most cases) and 3D coordination-polymeric networks from coordination polyhedra $\mathrm{Tl}(\mathrm{I})$-cyanoximates which are the most important for present discussion are shown in Figures 5-10. Since formation of a double-stranded, "ladder-type" 1D coordination polymer is the most common way of building the structure, we examined this topological motif in detail. A typical organization of such a motif consists of a centrosymmetric dimer (Figure 11(A)), with its $\mathrm{Tl}_{2} \mathrm{O}_{2}$ units 
fused together by additional, longer auxiliary third contact with the oxygen atom of the neighboring dimer to form a "ladder" (Figure 11(B)). This double-stranded zigzag chains form infinite columns that represent a 1D coordination polymer in which individual columns have no chemical bonding between them in the lattice (Figure 11(C)), but are instead connected by means of the van-der-Waals forces. There are two rhombs $\mathbf{1}$ and $\mathbf{2}$ in this "ladder" motif, which are different both by Tl---Tl, Tl---O distances, and by the bend angle $\delta$ (Figure 12). Details of the geometry of such topology for these polymers are summarized in Table 3 . The shortest intermetallic distance of $3.705 \AA$ among polymeric compounds was found in the Tl(3PCO) complex, which is very close to $3.456 \AA$ for metallic thallium.

Scheme 2. Observed binding modes in $\mathrm{Tl}(\mathrm{I})$ cyanoximates.

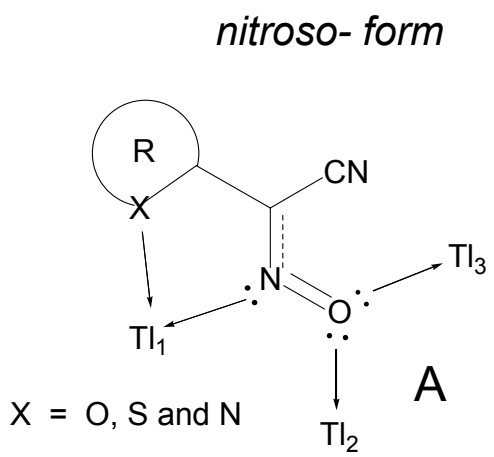

chelate $+\mu^{2}$-oxo-bridging

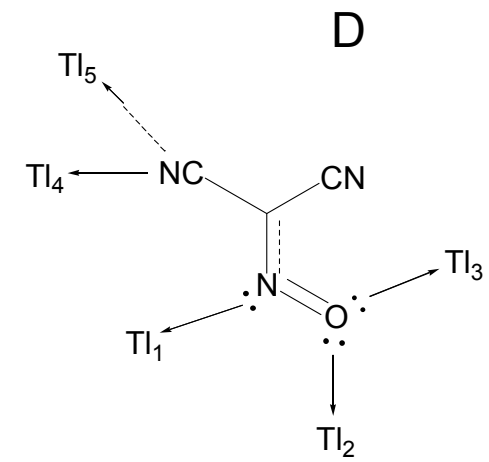

$\mu^{2}-\mathrm{N}, \mu(\mathrm{NO})+\mu^{2}$-oxo-bridging

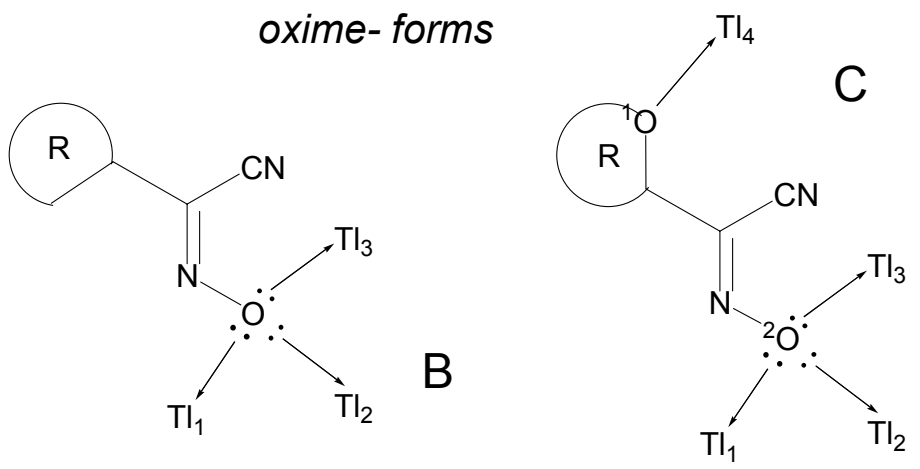

$\mu^{3}$-oxo-bridging

$\mu^{1}-O^{1}-\mu^{3}-O^{2}$-bisoxo-bridge

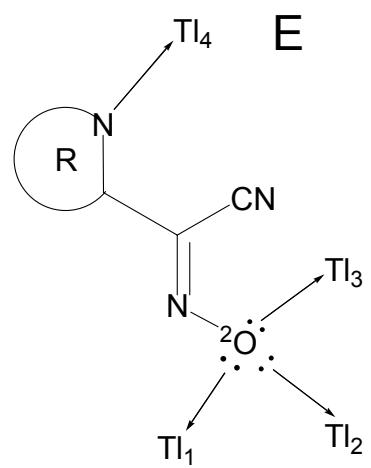

$\mu^{1}-N-$, and $\mu^{3}$-oxo-bridging

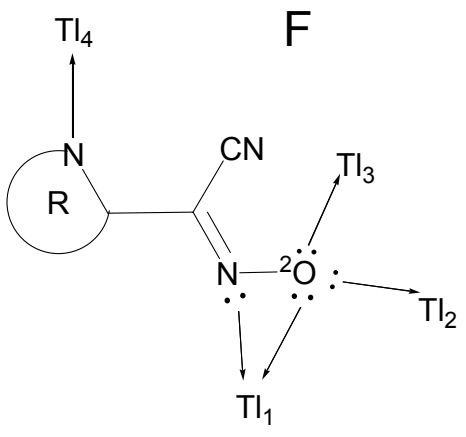

$\mu^{1}-N-, \mu^{3}$-oxo-bridging and $\mathrm{N}-\mathrm{O}$ "side-on" coordination

Figure 5. Organization of a zigzag chain in 2D-coordination polymer in the structure of $\mathrm{Tl}(\mathrm{BCO}) . \mathrm{H}$-atoms are omitted for clarity.

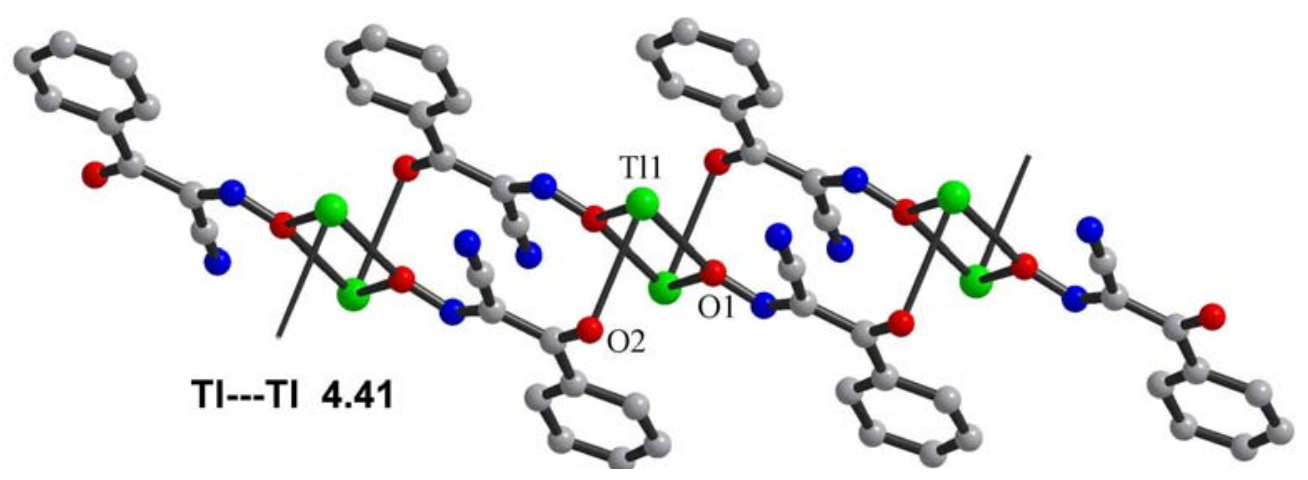


Figure 6. Organization of zigzag chain in 2D-coordination polymer in the structure of $\mathrm{Tl}(2 \mathrm{PCO})$. H-atoms are omitted for clarity.

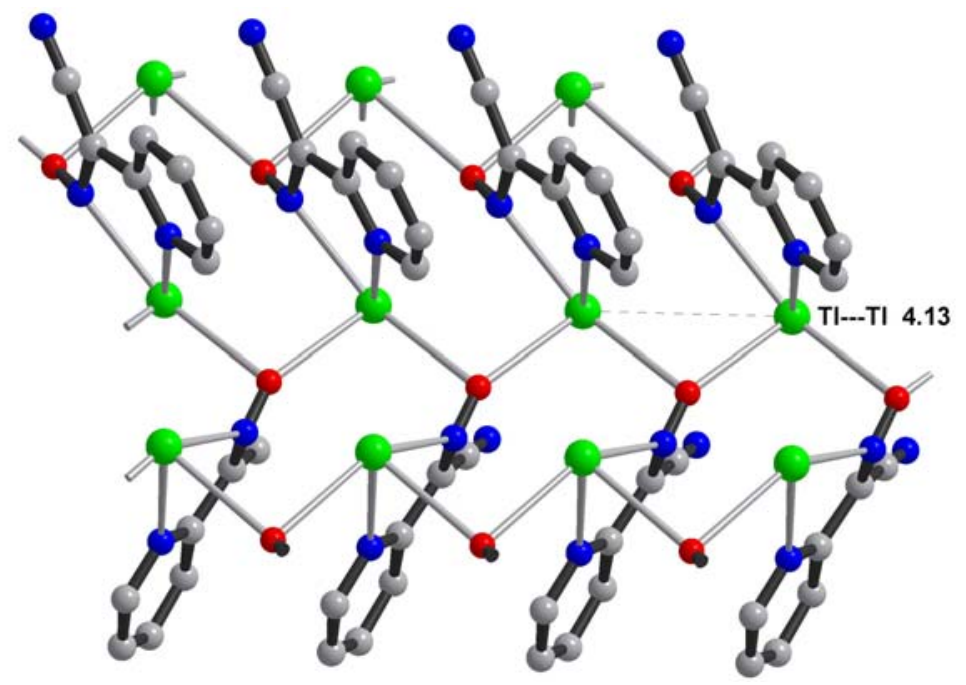

Figure 7. Organization of a double-stranded, ladder-type 2D sheets in this 3D-coordination polymeric structure of $\mathrm{Tl}(\mathrm{ACO})$.

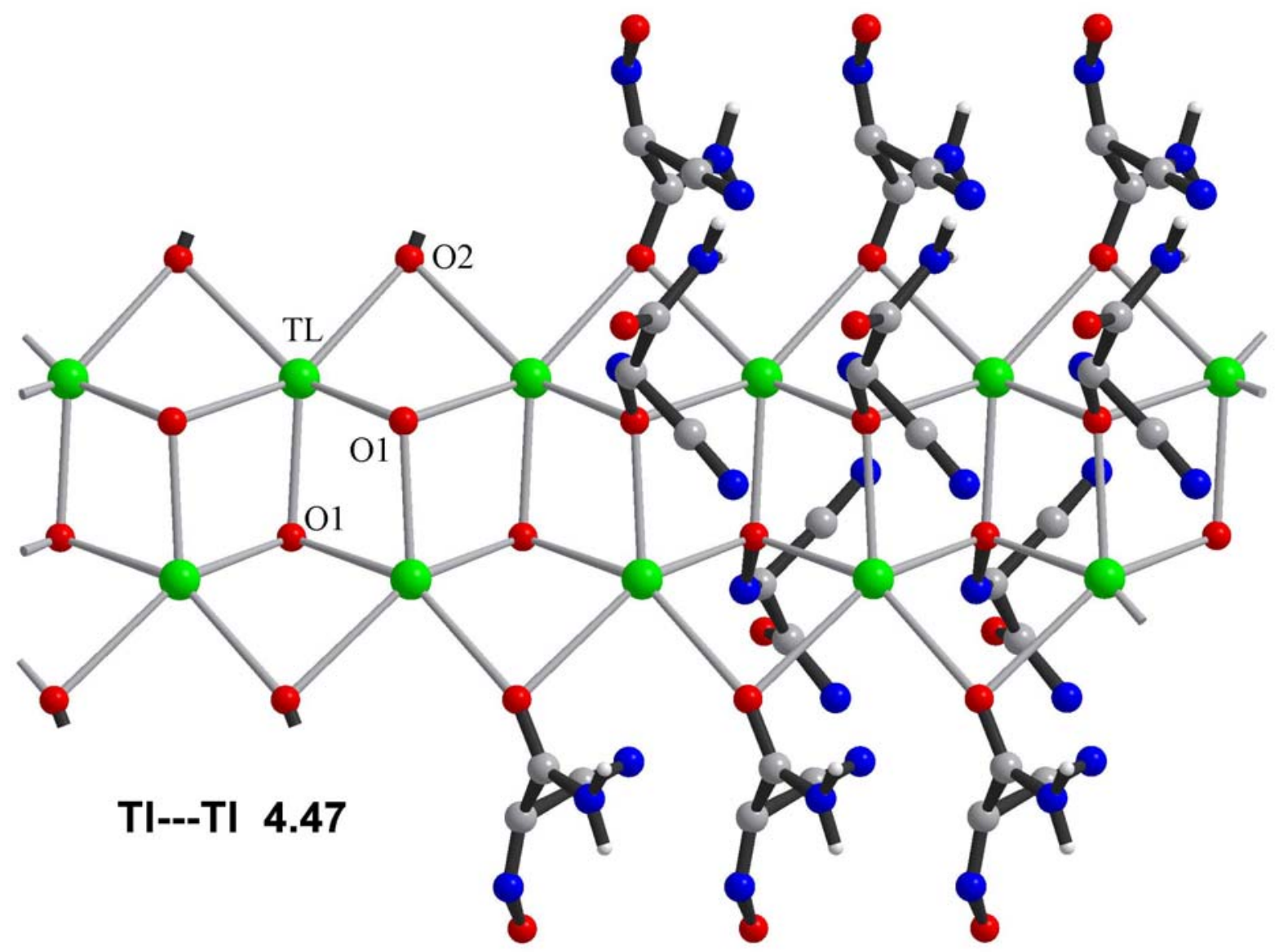


Figure 8. Organization of a complex, unique 2D-coordination polymeric sheets in the structure of $\mathrm{Tl}(\mathrm{PiCO})$. H-atoms are omitted for clarity.

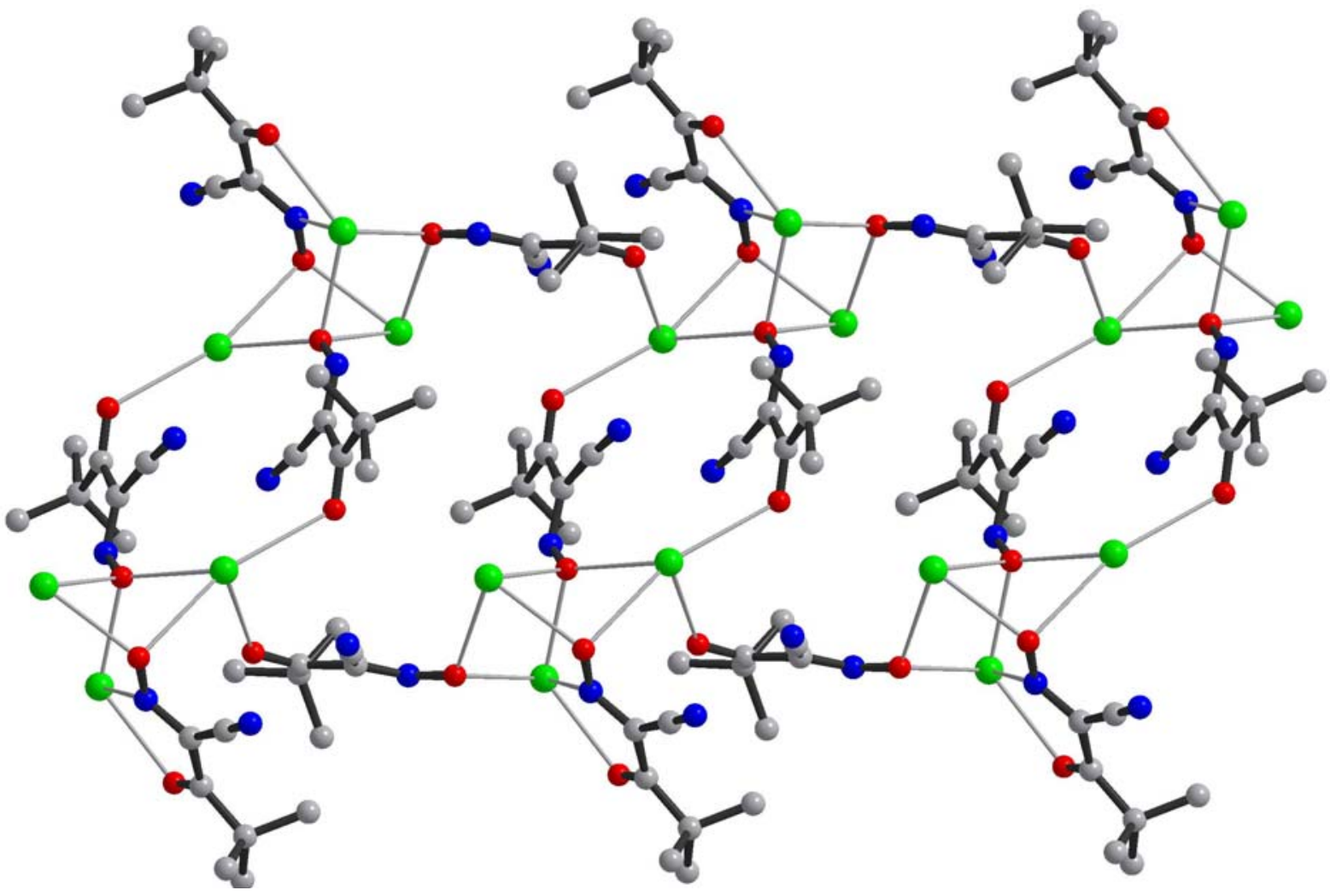

Figure 9. Two arbitrary projections of the crystal packing showing the organization of a $3 \mathrm{D}$ coordination-polymeric framework of $\mathrm{Tl}(\mathrm{CCO})$.
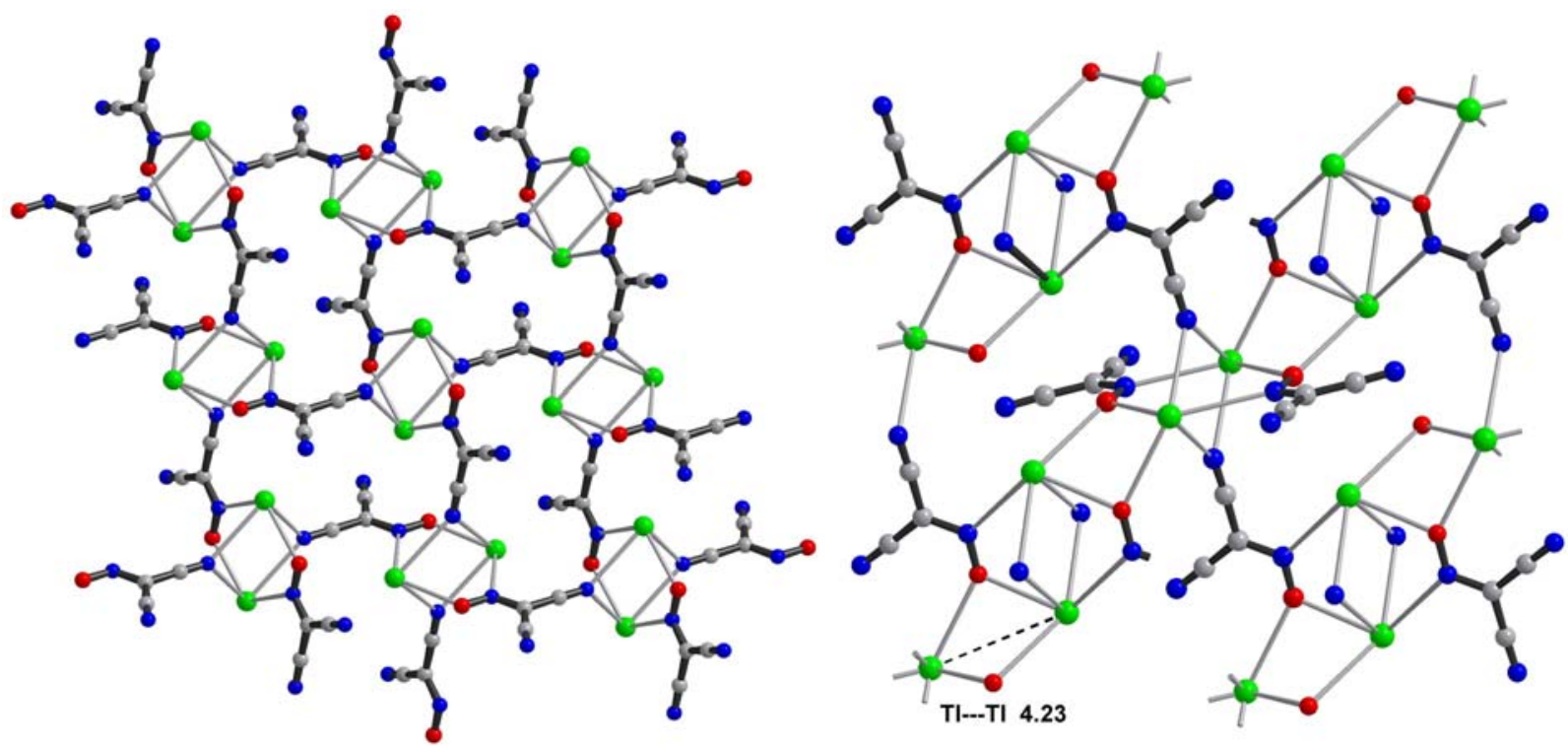
Figure 10. Organization of a layered type 2D coordination-polymeric structure of $\mathrm{Tl}$ (TDCO) by means of annealing of centrosymmetric $\mathrm{Tl}_{2} \mathrm{~S}_{2}$ rhombs via oxygen atoms of the nitroso group of neighboring anions into infinite stacks. Adjacent layers of complexes are connected only by van-der-Waals forces between N.N'-dimethyl-thioamde fragment.

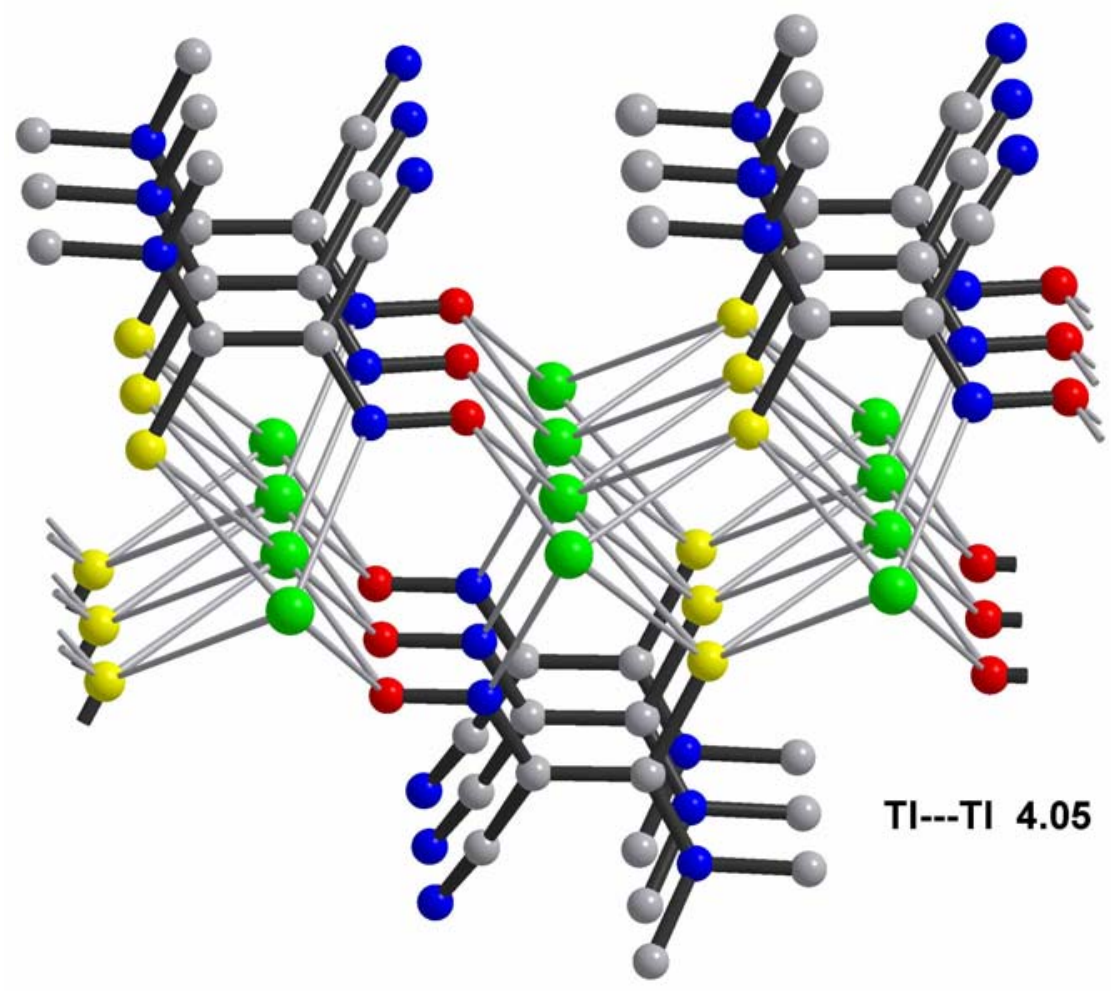

Figure 11. Structure of the centrosymmetric dimer $\mathrm{Tl}_{2} \mathrm{~L}_{2}$ (A), and its fusion into the double-stranded 1D "ladder type" coordination polymer $(\mathbf{B})$, which appears as a column in the structure $(\mathbf{C}$, view along $a$ ). An example of $\mathrm{Tl}(2 \mathrm{Cl}-\mathrm{PhCO})$ is shown. Individual infinite columns are connected with each other only via van-der-Waals contacts $(\mathbf{C})$; $\mathrm{H}$-atoms in $\mathbf{B}$ and $\mathbf{C}$ are not shown for clarity.
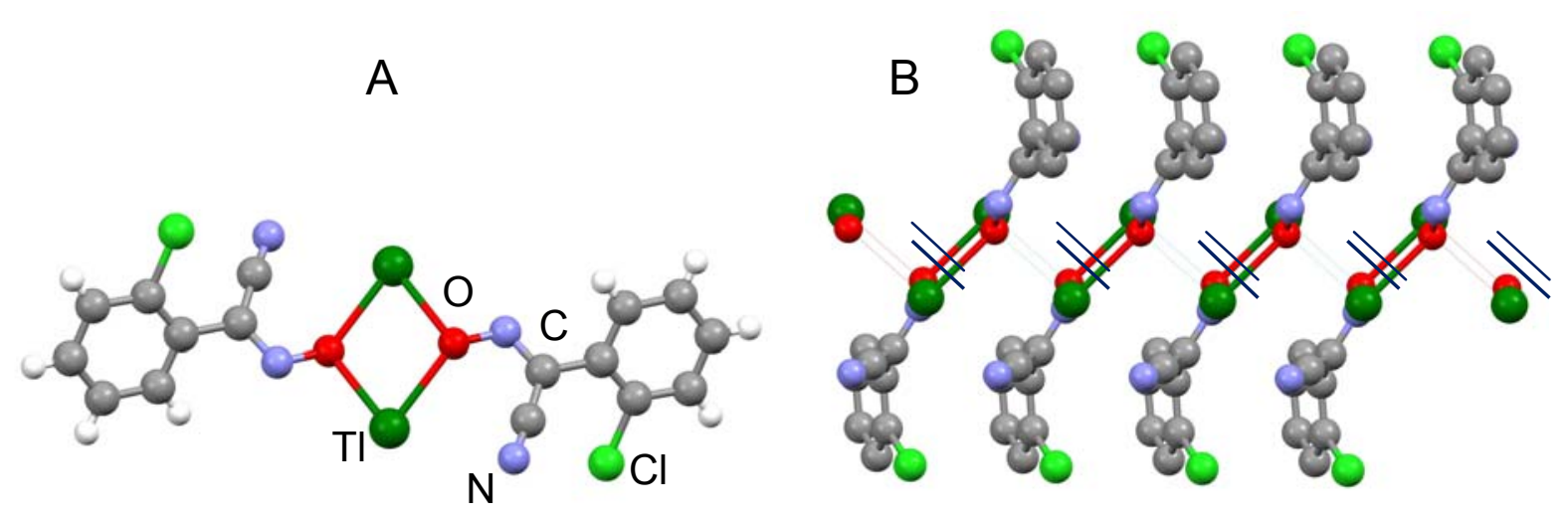
Figure 11. Cont.

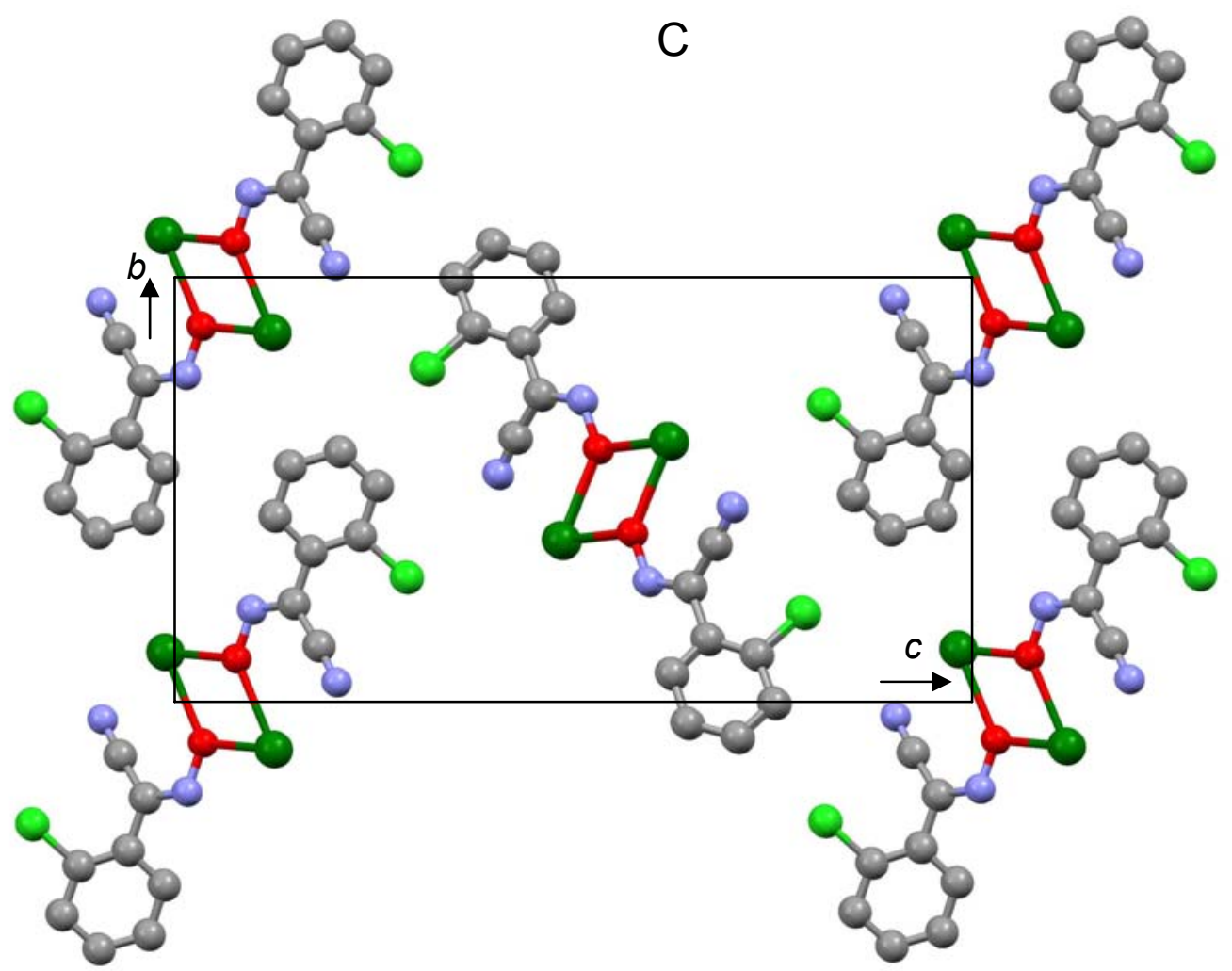

Figure 12. Typical double-stranded "ladder-type" polymeric motif in crystal structures of several TlL: two orthogonal views. The groups L are: monosubstituted-arylcyanoximes, such as $2 \mathrm{Cl}_{-} \mathrm{PCO}^{-}, 2 \mathrm{~F}-\mathrm{PhCO}^{-}, 4 \mathrm{Br}_{-} \mathrm{PhCO}^{-}$, and heteroarylcyanoximes such as $3 \mathrm{PCO}^{-}$, $4 \mathrm{PCO}^{-}, \mathrm{BTCO}^{-}$(from Figure 3).
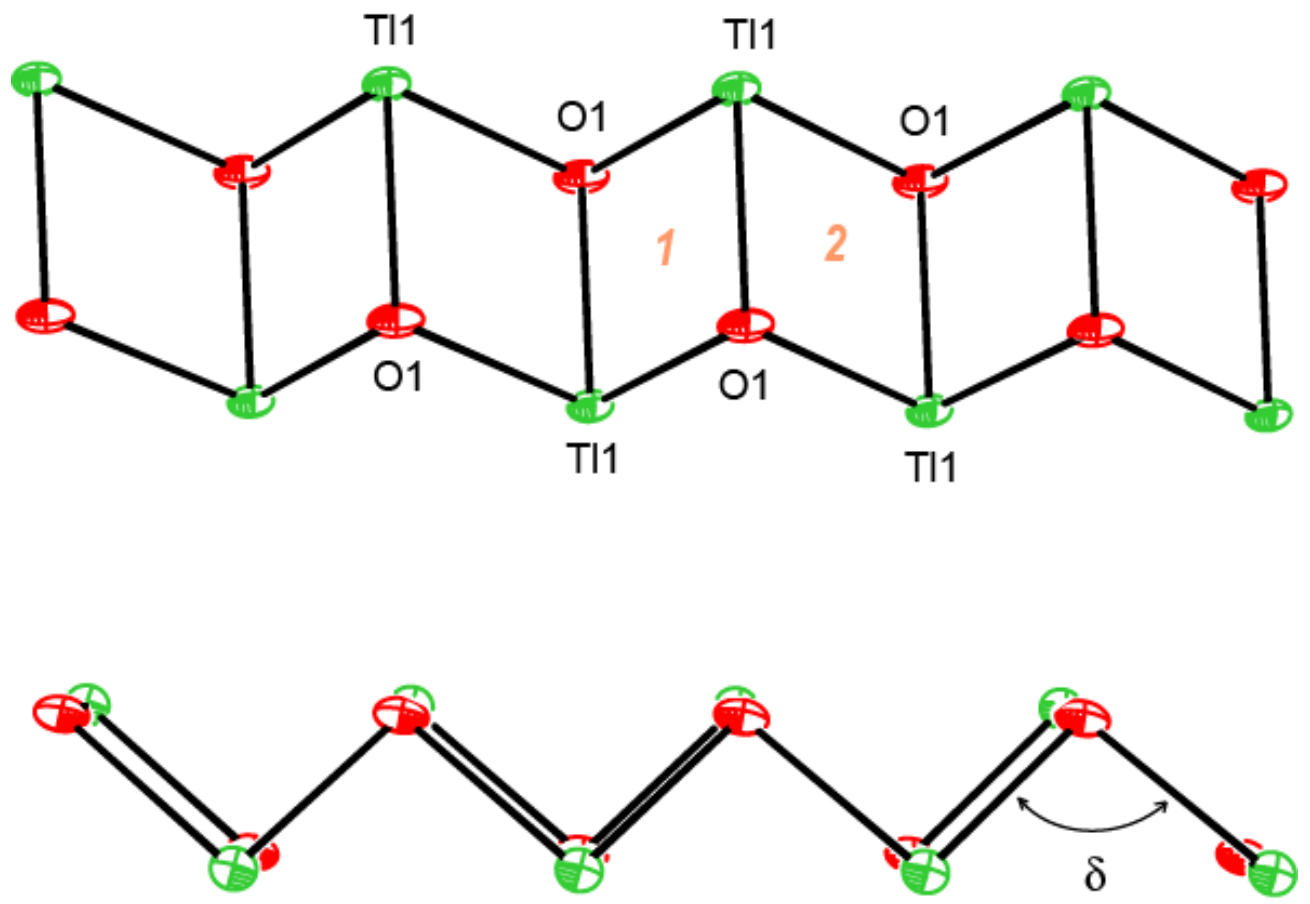
Table 3. Geometry of two different $\mathrm{Tl}_{2} \mathrm{O}_{2}$ fused rhombs ( 1 and 2) that are formed from the centrosymmetric (TIL) 2 dimers and define the double-stranded ladder-type motif of coordination polymer of several $\mathrm{Tl}(\mathrm{I})$ cyanoximates.

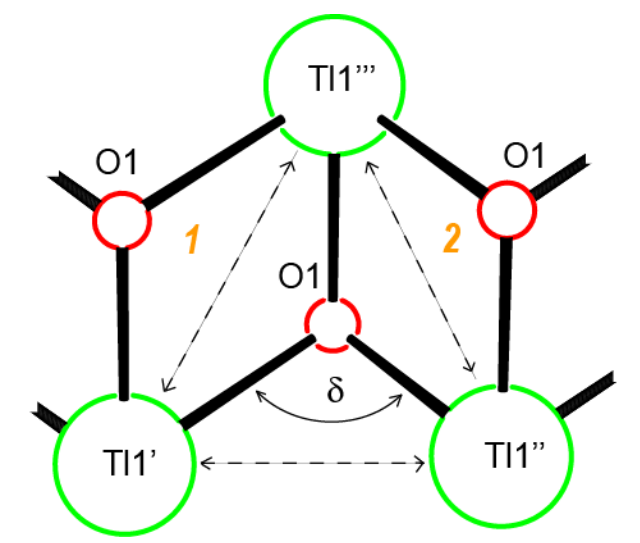

\begin{tabular}{|c|c|c|c|c|c|}
\hline Complex & Tl'---Tl', А̊ & Tl'---Tl'", $\AA$ & Tl'"---Tl'", $\AA$ & $\delta$ angle, $\left[{ }^{\circ}\right]$ & Ref. \\
\hline $\mathrm{Tl}(\mathrm{ACO})$ & 4.034 & 4.473 & 4.473 & 95.48 & [35] \\
\hline Tl(BTCO) & 4.428 & 4.329 & 4.767 & 107.35 & [12] \\
\hline $\mathrm{Tl}(3 \mathrm{PCO})$ & 3.736 & 3.705 & 4.571 & 70.86 & [71] \\
\hline $\mathrm{Tl}(4 \mathrm{PCO})$ & 3.899 & 3.899 & 4.418 & 92.47 & [71] \\
\hline $\mathrm{Tl}(2 \mathrm{Cl}-\mathrm{PhCO})$ & 3.838 & 4.184 & 4.440 & 90.70 & [22] \\
\hline $\mathrm{Tl}(4 \mathrm{Br}-\mathrm{PhCO})$ & 4.058 & 4.097 & 4.435 & 99.92 & {$[22]$} \\
\hline $\mathrm{Tl}(2 \mathrm{~F}-\mathrm{PhCO})$ & 4.113 & 4.114 & 4.301 & 101.37 & \\
\hline
\end{tabular}

Among other structural peculiarities of $\mathrm{Tl}(\mathrm{I})$ cyanoximates described here, should be mentioned an extensive H-bonding in the structure of the Tl(ACO) complex (ESI 11), which joins individual 2D double-stranded sheets into a robust, thermally stable coordination polymer. In the structure of tetrameric Tl(TLCO) (Figure 3: 2-cyanoxime-4-methyl-thiazol, 19) there are two types of the oxime groups: two are disordered over two positions, which makes the geometry of this fragment rather unusual, while the other two are ordered and act as chelating and bridging groups (ESI 12).

Several reference sources provide slightly different values of ionic radii for oxygen, nitrogen and thallium(I) $[37,38]$, so we used in our calculations the most current values available from the online source [27] which are now presented in Table 1. Therefore, all Tl-O distances in the synthesized Tl(I) cyanoximates shorter than $2.88 \AA$ and all Tl-N distances shorter than $2.96 \AA$ were considered as bonds, while longer distances were commented on as electrostatic contacts which are helping in crystal packing in the structures of these mostly ionic complexes.

It should be noted that the staircase architecture was observed by Harrowfield in $\mathrm{Tl}(\mathrm{I})$ complexes with nitrobenzoates $[39,40]$. However, this motif we reported first in the structure of $\mathrm{Tl}(\mathrm{ACO})$ complex [35]. Also, a very similar structural motif was found in numerous $\mathrm{Cu}(\mathrm{I})$ halides and pseudohalides compounds containing neutral N-heterocyclic ligands [41-44] (and references in [41,43]) with several complexes showing quite remarkable photoluminescence properties.

\subsection{Aspects of Applications of Tl-Based Coordination Polymers}

Delocalized mixed valence compounds $[45,46]$ have great potential as electric conductors. Discovery of highly conductive non-metallic substances and reliable superconducting material 
promises great reduction in future energy and materials consumption for transportation and use of electricity. Conductive coordination polymers based on an organic ligands network, promise certain advantages over semiconductors and metals/alloys since they can be applied as thin films as opposed to the bulk material. These conductive films alleviate the problem of heat dissipation in miniature electronic devices, while bulk materials practically are at the limit of their sizes and applications due to this problem of efficient heat removal. An electron transfer (hopping) between different oxidation states (ESI 13) is a key phenomenon in electric conductivity of mixed valence compounds [23]. Thallium is especially attractive since it has two electrons transition $\mathrm{Tl}^{+} \Leftrightarrow \mathrm{Tl}^{3+}$ from the top $6 \mathrm{~s}-6 \mathrm{p}$ valence shell; these electrons are thought to be coherent and form a pair similar to that offered by Cooper [47]. Established by Zusman [48] and Tsirlina [49] values for the rate of the $\mathrm{Tl}^{+} / \mathrm{Tl}^{3+}$ transition are $\sim 2 \times 10^{3} \mathrm{~s}^{-1}$ and $\Delta \mathrm{G} \sim 0.76 \mathrm{ev}\left(\sim 6,130 \mathrm{~cm}^{-1}\right)$ making a formation of mixed valence thallium based coordination polymers that show electron hopping to be achievable.

There are several important factors that guide the search for mixed valence coordination polymers that may exhibit an electrical conductivity and even lead to high-temperature superconductivity. These are: (1) the formation of well-organized one-dimensional polymeric motifs such as columns, chains, or narrow sheets connected by non-bonding interactions, which is important for the prevention of the "charge leakage" in other than main directions; (2) the close spatial location of metal ions in the crystal lattice due to appropriate bridging atoms/groups, or direct metal-metal interactions; and (3) similar coordination geometries and bonding properties for metal centers in different oxidation states. The latter property leads to a low energy barrier between two different oxidation states and creates the condition for electron transport (hopping) [23], induced by light or temperature. Thus, one of the key conditions for success in the search for conducting mixed valence compounds and materials is the discovery and exploration of new bridging ligand systems that can assure formation of the one-dimensional polymeric structures of complexes.

The data that has been reported here represents a summary of the first stage of our project aimed at the preparation of mixed valence Tl-based conducting coordination polymers. We have developed a method of synthesis of $\mathrm{Tl}(\mathrm{I})$ polymers and performed their extensive characterization, analyzed structures and identified the most promising structural motif — double stranded "ladder-type"—with closest intermetallic separations. The next step will be the generation of mixed valence polymeric compounds using chemical or electrochemical methods. A successful realization of this project will add highly thermally stable conducting coordination polymers to the arsenal of tools for microelectronics and molecular electronics. Apparent toxicity of Tl-compounds should not preclude their practicality since similarly toxic arsenides (GaAs, and related) and selenides ( $\mathrm{ZnSe}, \mathrm{CdSe}$ ) and tellurides $(\mathrm{PbTe}, \mathrm{CdTe})$ are widely used today in closed, non-serviceable electronic devices with limited access to their components.

\section{Polymeric $\operatorname{Ag}(I)$ Cyanoximates}

\subsection{Synthesis of Complexes and Their Properties}

The preparation of polymeric silver(I) complexes from protonated cyanoximes HL represents a simple procedure depicted in the Scheme 3. The deprotonation of cyanoximes with the base (typically $\mathrm{NaOH}$, or $\mathrm{K}_{2} \mathrm{CO}_{3}$ ) leads to yellow solutions of respective conjugated anions $[19,20,50]$, which rapidly, 
within seconds react with aqueous $\mathrm{AgNO}_{3}$ to form silver(I) cyanoximates of $\mathrm{AgL}$ composition. In all cases resulting complexes are thick, sparingly soluble in aqueous solutions precipitates of various colors that and can be easily separated from the reaction mixture by filtration, washed with water and cold methanol and dried in vacuum desiccator over $\mathrm{H}_{2} \mathrm{SO}_{4}(\mathrm{c})$. Yields are typically above $90 \%$. However, silver(I) cyanoximates with thioamides $\mathrm{TCO}^{-}$and $\mathrm{TDCO}^{-}$(4 and 5, Figure 3) cannot be obtained due to the fast decomposition to black $\mathrm{Ag}_{2} \mathrm{~S}$. Some physical-chemical characteristics and crystal data for characterized up-to-date AgL are presented in Table 4. All currently known silver(I) cyanoximates are not soluble in hydrocarbons, ether, THF and chlorohydrocarbons. However, solid $\mathrm{AgL}$ are dissolve in an excess of aqueous solutions of $\mathrm{KCN}, \mathrm{Na}_{2} \mathrm{~S}_{2} \mathrm{O}_{3}$ and ammonia with the loss of their solid state structures. Thus, $\left[\mathrm{Ag}(\mathrm{CN})_{2}\right]^{-},\left[\mathrm{Ag}\left(\mathrm{S}_{2} \mathrm{O}_{3}\right)_{2}\right]^{3-}$ anionic complexes, and $\left[\mathrm{Ag}\left(\mathrm{NH}_{3}\right)_{2}\right]^{+}$ cationic complex [20] are formed similarly to those generated from silver(I) halides [35]. This turned to be an important property for the equipment and glassware clean-up for the last two reagents.

Scheme 3. Synthesis of silver(I) cyanoximates.

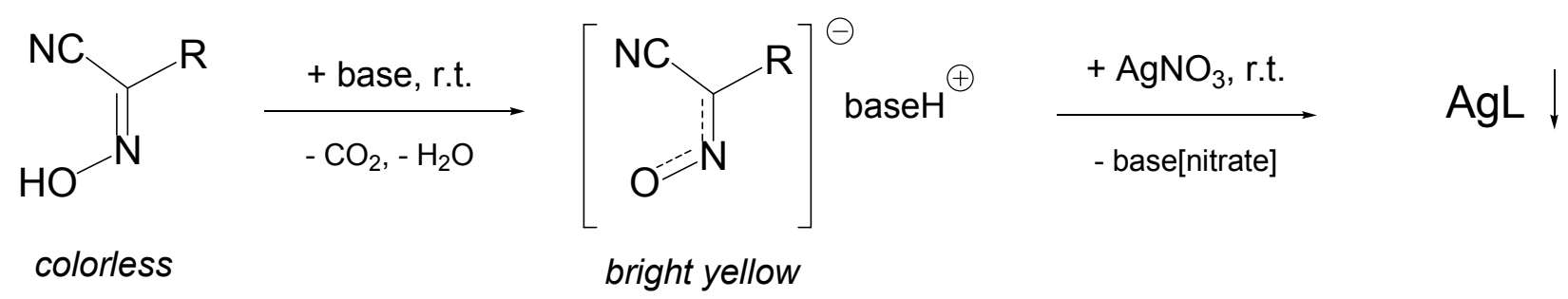

Again, like silver(I) halides and pseudohalides [17,25], solid AgL are soluble in neat amines such as pyridine and its methylated homologs, aqueous $\mathrm{NH}_{3}$ and methylamines, and also easily dissolved in strong donor solvents such as DMSO, DMF and hexamethylphosphoramide (HMPA). A rapid addition of $\sim 10: 1$ by volume excess of ether to these solutions results in precipitation of unstable amorphous $\mathrm{AgL} \cdot 2 \mathrm{Solv}$ (Solv = DMSO, HMPA ans DMF) complexes that slowly lose the solvent and return to the starting AgL compounds [51]. Values of the electrical conductivity for solutions of AgL in strong donor solvents are close to those for 1:1 electrolytes and evidence the loss of solid state structures [19]. Finally, silver(I) cyanoximates also react with phosphines and stibines to form rather unusual monomeric tetracoordinated complexes [52].

All 37 silver(I) cyanoximates (Figure 3) are known with many of them being not surprisingly light-sensitive compounds. However, there is a large group of 13 visible light insensitive $\mathrm{AgL}$ complexes, namely with $\mathrm{L}=\mathrm{CCO}^{-}, \mathrm{ACO}^{-}, \mathrm{DCO}^{-}, \mathrm{ECO}^{-}, \mathrm{PiCO}^{-}, \mathrm{BCO}^{-}, \mathrm{MCO}^{-}, \mathrm{BiPiPCO}^{-}, 2 \mathrm{PCO}^{-}$, $\mathrm{BTCO}^{-}, \mathrm{BIMCO}^{-}, \mathrm{BIHCO}^{-}, \mathrm{BOCO}^{-}$cyanoximes (Figure 3), which are stable to day light for years of continuous exposure (ESI 14). This property has several important practical implications [19-21] which will be briefly discussed further in this work.

\subsection{Solid State Structures}

Because of the practicality of the aforementioned thirteen light-stable complexes, a considerable effort has been made to characterize these complexes in solid state. Therefore, in recent years seven crystal structures of complexes with $\mathrm{AgL}$ composition were determined [19-21], as well as three crystal structures of solvates of $\mathrm{AgL} \cdot \mathrm{S}$ composition [51] $(\mathrm{L}=\mathrm{BOCO}, \mathrm{S}=\mathrm{DMF} ; \mathrm{L}=\mathrm{BOCO}$, 
$\mathrm{S}=$ DMSO; $\mathrm{L}=\mathrm{BTCO}, \mathrm{S}=\mathrm{H}_{2} \mathrm{O}$ ). It should be noted, however, that the growth of crystals of silver(I) cyanoximates that are suitable for the X-ray analysis is a challenge due to their polymeric nature and, therefore, low solubility in common organic solvents and water. Frequently numerous attempts and considerable time are required to obtain specimens of X-ray diffraction quality. We found that the best results were obtained using two methods: (1) quick hot filtration of an aqueous solution, saturated with appropriate $\mathrm{AgL}$, into the test tube submerged into the thermostat with subsequent slow cooling of the solution within 4-5 days; this approach worked surprisingly well for $\mathrm{Ag}(\mathrm{CCO}), \operatorname{Ag}(\mathrm{ACO}), \operatorname{Ag}(\mathrm{PiCO})$ and $\mathrm{Ag}(\mathrm{BCO})$ complexes; (2) overlay of saturated $\mathrm{CH}_{3} \mathrm{CN}$, DMSO or DMF solutions of AgL with ether at room temperature; this method was used for the growth of crystals of $A g(E C O), A g(D C O)$ and solvates such as $\mathrm{AgL} \cdot \mathrm{S}\left(\mathrm{L}=\mathrm{BOCO}, \mathrm{S}=\mathrm{DMF} ; \mathrm{L}=\mathrm{BOCO}, \mathrm{S}=\mathrm{DMSO} ; \mathrm{L}=\mathrm{BTCO}, \mathrm{S}=\mathrm{H}_{2} \mathrm{O}\right)$. Actual microscopic photographs of single crystals of some AgL are presented in ESI 14 C,D. No darkening of any single crystals of the studied complexes upon exposure to $\mathrm{X}$-rays $(\mathrm{Mo}, \mathrm{K} \alpha)$ during data collection was detected.

The binding modes of cyanoxime anions in the structures of silver(I) complexes that were experimentally observed are summarized in Scheme 4 and indicate their bridging mode for compounds without heterocyclic groups R (Scheme 4). In these complexes extended coordination polymers are formed. At the same time, for the 2-heterocyclic ligands $\mathrm{BOCO}^{-}$and $\mathrm{BTCO}^{-}$in their solvate complexes the chelate function is the most preferable way of their coordination to silver(I) atoms, although the bridging function of the nitroso- group is clearly present in two cases as well. In all these complexes - $\mathrm{Ag}(\mathrm{BOCO}) \cdot \mathrm{DMSO}, \mathrm{Ag}(\mathrm{BOCO}) \cdot \mathrm{DMF}$ and $\mathrm{Ag}(\mathrm{BTCO}) \cdot \mathrm{H}_{2} \mathrm{O}$ - there is also a disordered by two positions CNO group [51]. The first two complexes represent dimers, while the latter is a tetramer, and, hence, they formally do not belong to coordination polymers and will not be further discussed in this paper.

Scheme 4. Observed binding modes in polymeric silver(I) cyanoximates.
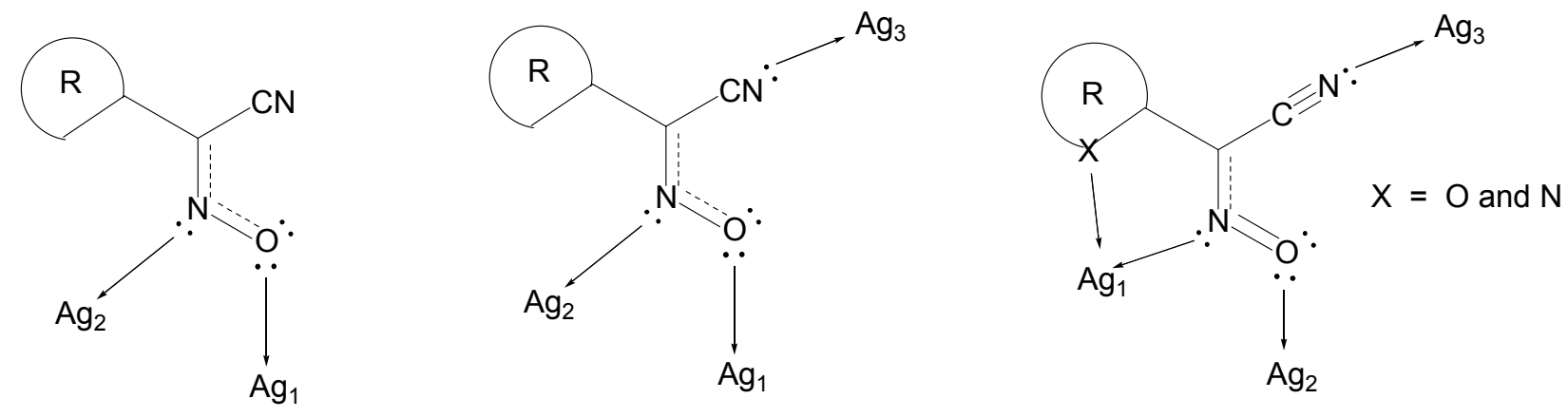

$Y=O$ and $S$
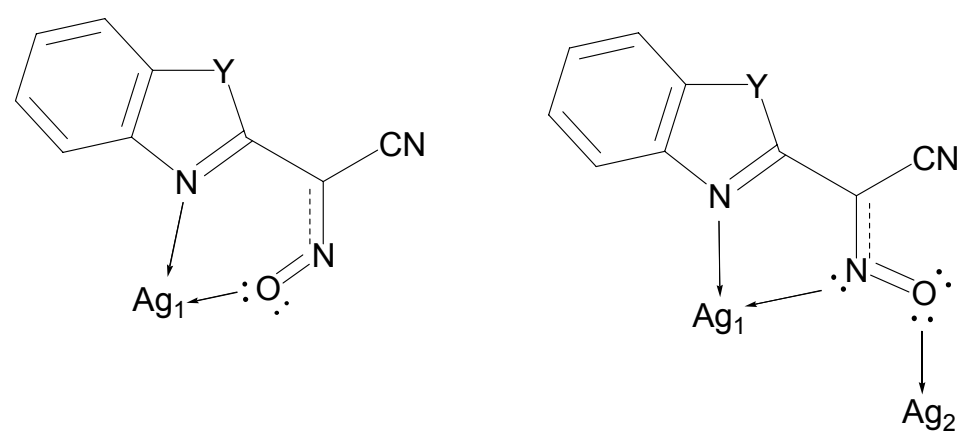
Table 4. Some chemical-physical parameters and crystal structures data for known polymeric $\mathrm{Ag}(\mathrm{I})$ cyanoximates.

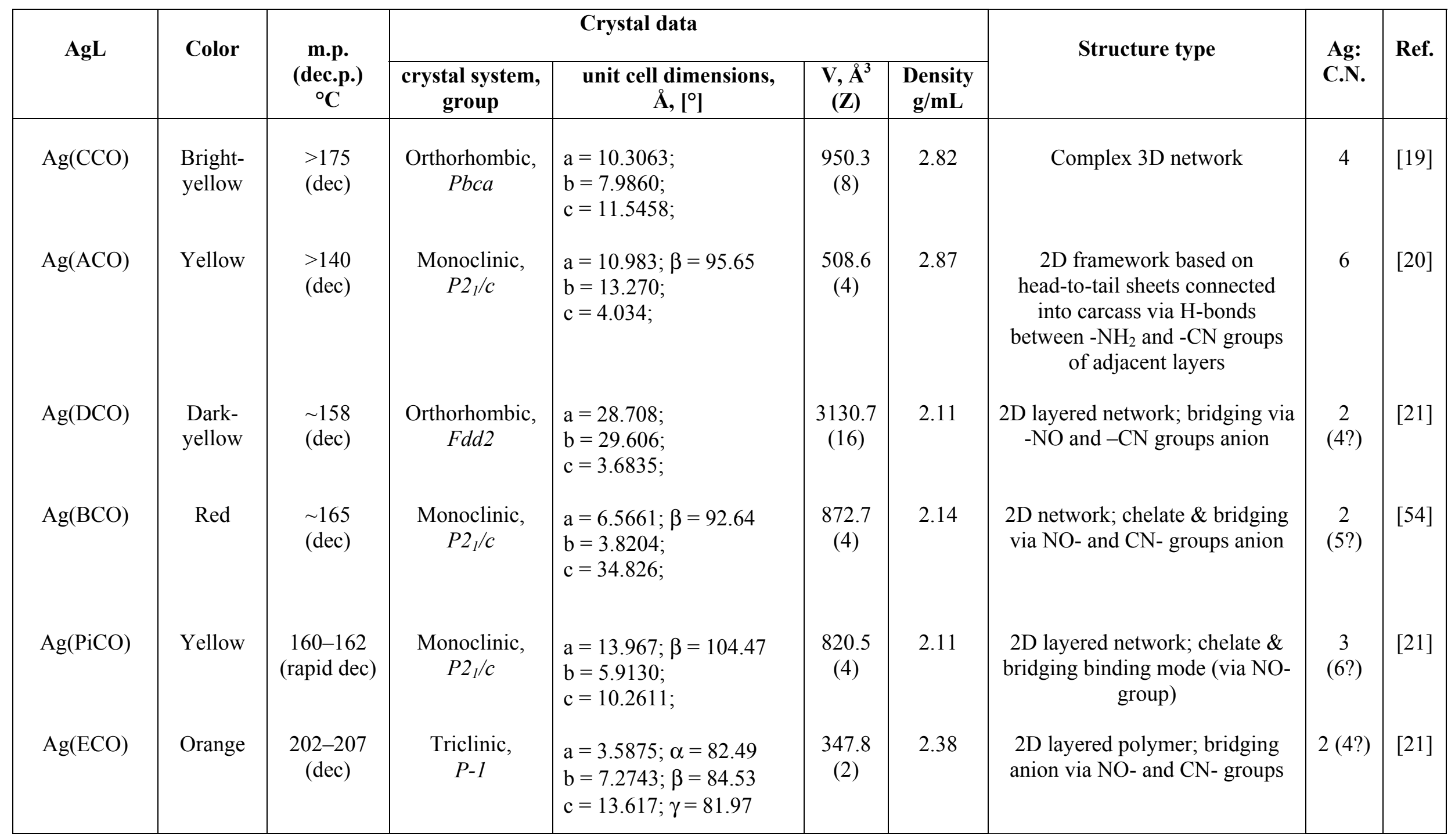


The most important chemical-physical and crystal data for studied the polymeric silver(I) cyanoximates of AgL composition that have been studied up-to-date are summarized in Table 4. There is a variety of both coordination numbers, ranging from two to eight, and shapes of coordination polyhedra in studied polymeric silver(I) cyanoximates. These "building blocks" are presented in the ESI 15-20, and detailed description of the peculiarities of their geometry is out of the scope of this work. It should be noted, though, that the shortest metal-ligand contacts are almost always Ag-N bonds from nitroso- and cyano- groups of bridging cyanoxime anions. These primarily covalent bonds are shorter than the sum of ionic radii and are arranged in practically linear fashion in structures of $\mathrm{Ag}(\mathrm{DCO}), \mathrm{Ag}(\mathrm{BCO})$ and $\mathrm{Ag}(\mathrm{ECO})$ with $\mathrm{N} 1-\mathrm{Ag}-\mathrm{N} 2$ angles between 160 and $166^{\circ}$ (ESI 15-17). There are also two, or three (like in $\operatorname{Ag}(\mathrm{PiCO})$ (ESI 18) and $\mathrm{Ag}(\mathrm{BCO})$ (ESI 17)) significantly longer than the sum of their ionic radii Ag---O contacts which have electrostatic origin and help in stabilization of a crystal lattice [21]. With those two (or three) longer distances the coordination polyhedra of silver(I) can be viewed as seesaw for $\operatorname{Ag}(\mathrm{DCO})$ and $\operatorname{Ag}(\mathrm{ECO})(E S I 15,16)$, or as distorted trigonal bipyramid for $\mathrm{Ag}(\mathrm{BCO})$, or distorted trigonal prism in the structure of $\mathrm{Ag}(\mathrm{PiCO})$ respectively $(E S I$ 17, 18). The coordination number of the central atom in $\mathrm{Ag}(\mathrm{CCO})$ is four in the distorted $\left[\mathrm{AgN}_{3} \mathrm{O}\right.$ ] tetrahedron [19] (ESI 19), while in $\mathrm{Ag}(\mathrm{ACO})$ it is six despite two very short $\mathrm{Ag}$--- $\mathrm{Ag}$ distances of $3.193 \AA$ [20] (ESI 20). These are typical of argentophilic interactions ranging from 2.9 to $3.3 \AA$ and are well documented in the literature [53].

Figure 13. Fragments of 3D-polymeric structure of $\operatorname{Ag}(\mathrm{CCO})$ : (a) unit cell content view along $c$; (b) view along $b$ direction. Coloring scheme here and in all following figures describing silver(I) cyanoximates: Ag—magenta, $\mathrm{N}$ — blue, $\mathrm{O}$ - red, $\mathrm{C}$ - grey, $\mathrm{H}$-white.

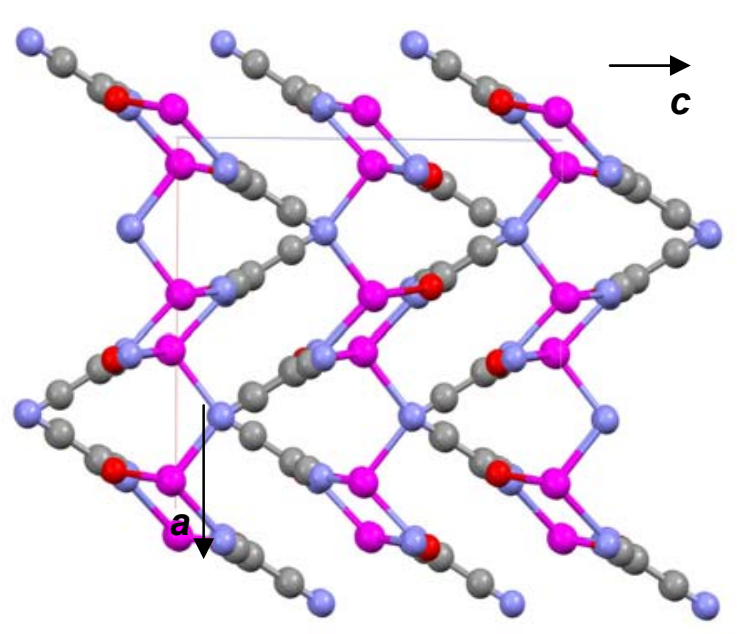

(a)

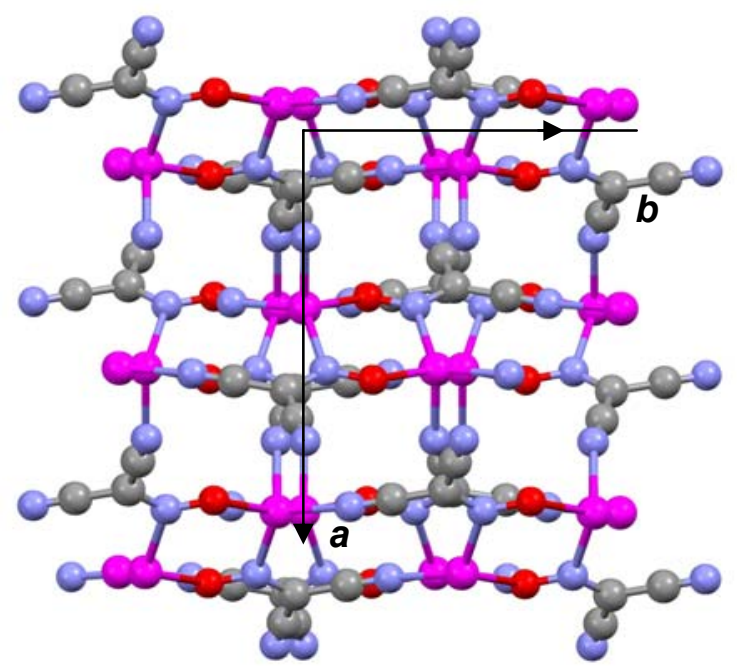

(b)

The most important motif in crystal structures of $\mathrm{Ag}(\mathrm{I})$-cyanoximates is a formation of complex 2D layered polymers with only one exception of well-defined 3D network in the case of $\operatorname{Ag}(\mathrm{CCO})$ [19] (Figure 13). Organization of very elegant, and yet completely different $2 \mathrm{D}$ coordination polymers in the structures of $\operatorname{Ag}(\mathrm{ACO}), \operatorname{Ag}(\mathrm{BCO}), \operatorname{Ag}(\mathrm{DCO}), \operatorname{Ag}(\mathrm{ECO})$ and $\mathrm{Ag}(\mathrm{PiCO})$ is shown in Figures 14-18 respectively. In all these cases $2 \mathrm{D}$ sheets of different complexity and composition are connected into the framework either by means of extensive H-bonding like in the structure of $\operatorname{Ag}(\mathrm{ACO})$ [20] (Figure 14), or by means of van-der-Waals interactions C-H---H-C (aromatic) between phenyl groups 
in the structure of $\mathrm{Ag}(\mathrm{BCO})$ [54] (Figure 15), or via C-H---H-C (aliphatic) interactions between ethoxy- and $t$-butyl- groups in structures of $\mathrm{Ag}(\mathrm{ECO})$ and $\mathrm{Ag}(\mathrm{PiCO})$ [21] (Figures 17, 18 respectively). An interesting case of electrostatic interlayer attractions between oxygen atoms of the nitroso- group and hydrogen atoms of methyl groups of the anion was determined in the structure of $\operatorname{Ag}(\mathrm{DCO})$ [21] (Figure 16).

Figure 14. Organization of 2D, layered polymeric structure of $\operatorname{Ag}(\mathrm{ACO})$ : one layer of "head-to-tail" packed molecules of the complex (A) and two views of multiple unit cells along $a(\mathbf{B})$, and $b$ directions (C) showing H-bonding (dashed lines) between layers.

A

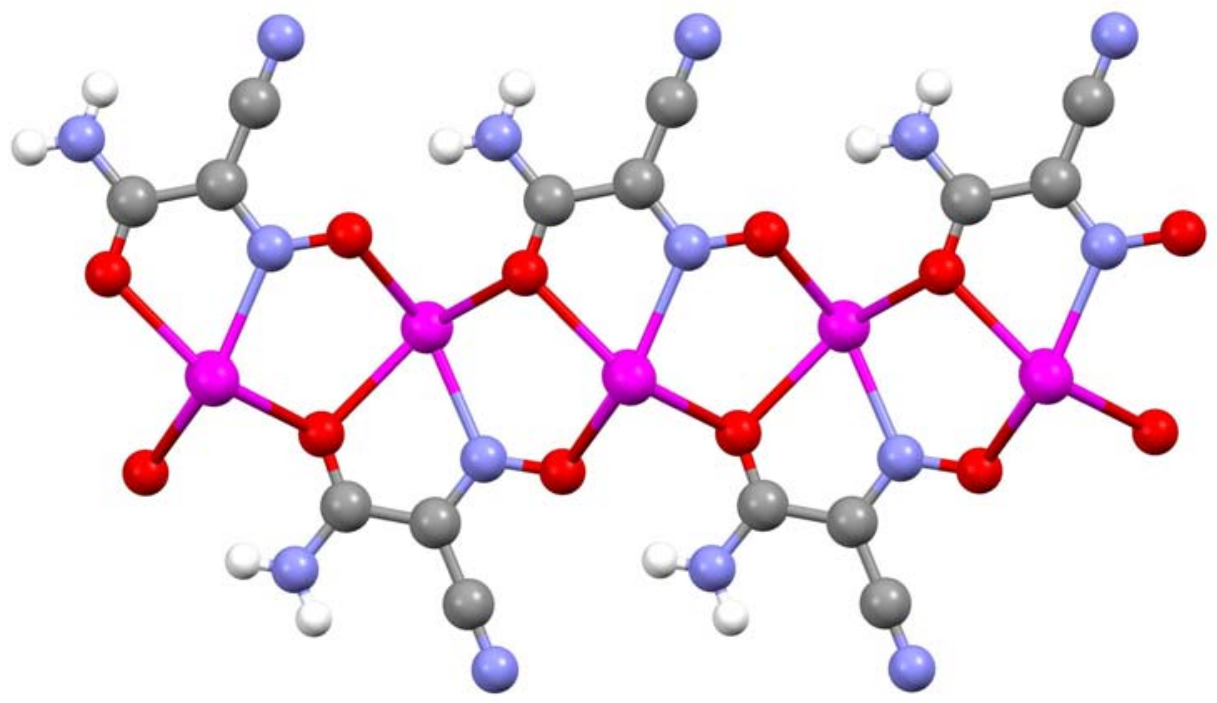

B

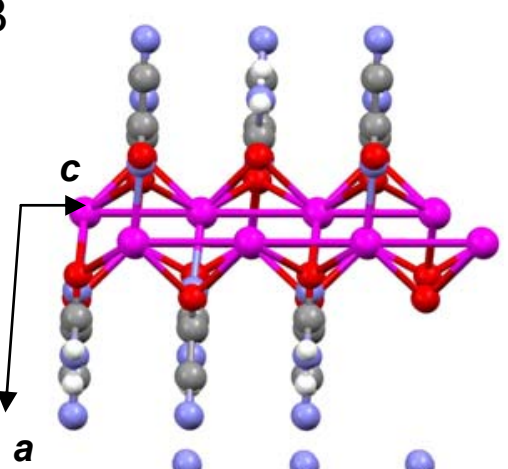

a

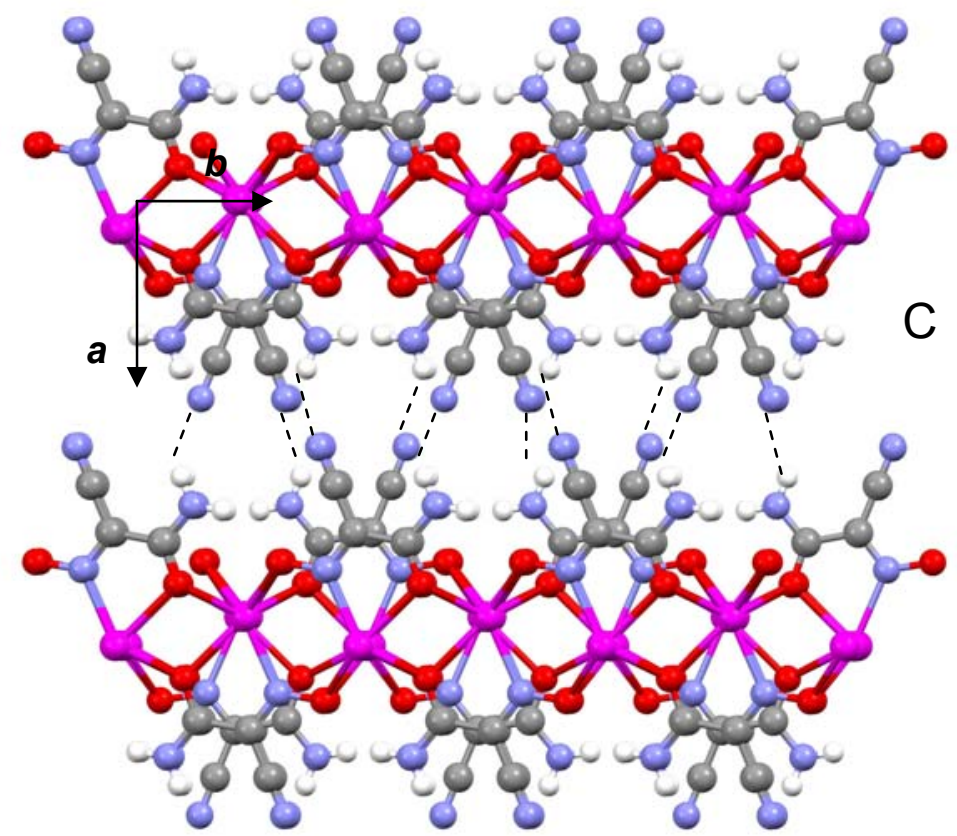


Figure 15. Organization of layered 2D structure of $\operatorname{Ag}(B C O)$ : view of two unit cells along $b$ showing polymeric motif (A), and $a b$ diagonal view of two unit cells (B). H-atoms are omitted for clarity.

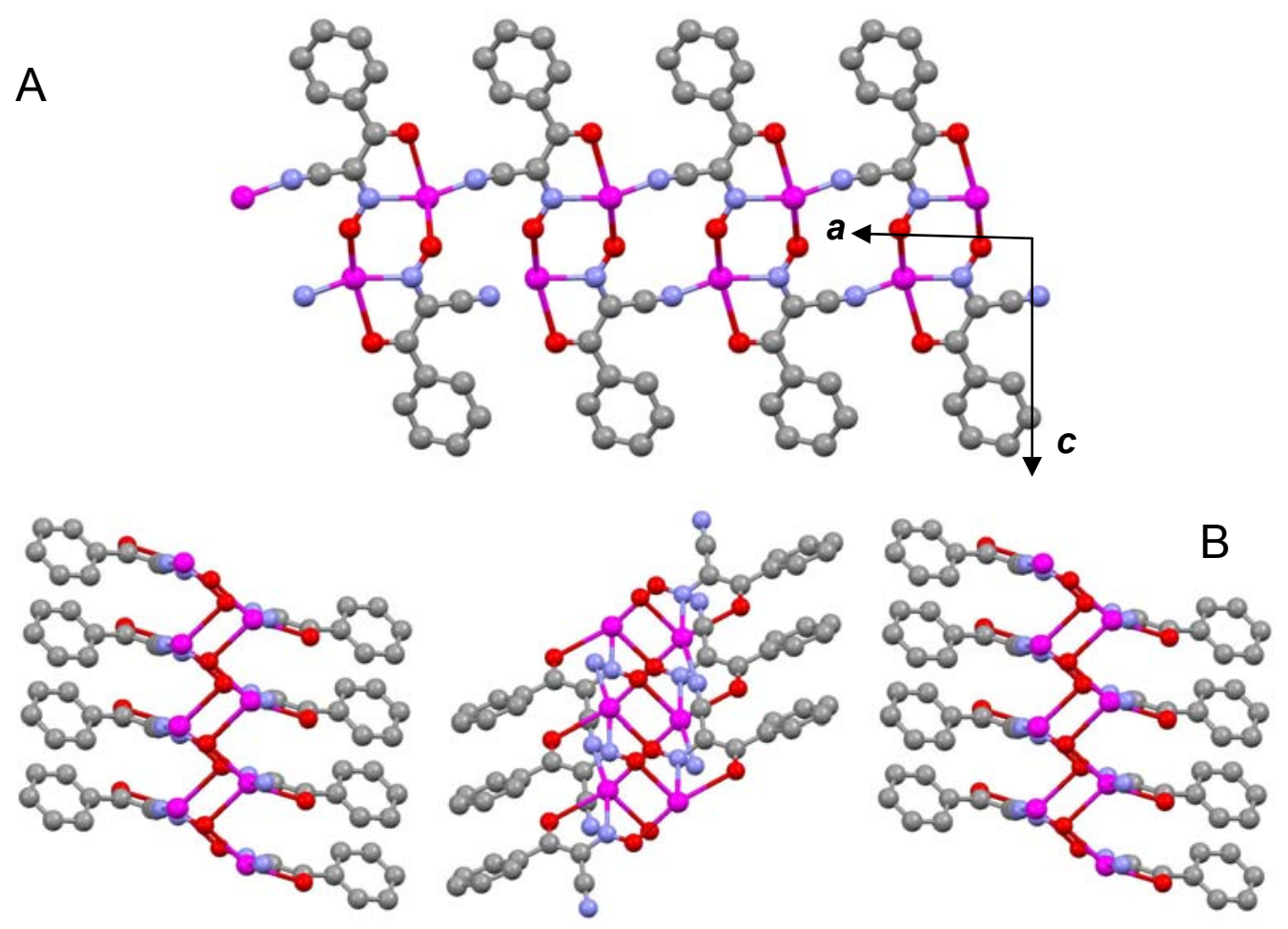

Figure 16. Organization of layered $2 \mathrm{D}$ structure of $\operatorname{Ag}(\mathrm{DCO})$ : view of ten unit cells along $c$ direction showing polymeric motif (A), and then view of the same ten unit cells along $b$ (B) in which $\mathrm{H}$-atoms are omitted for clarity.

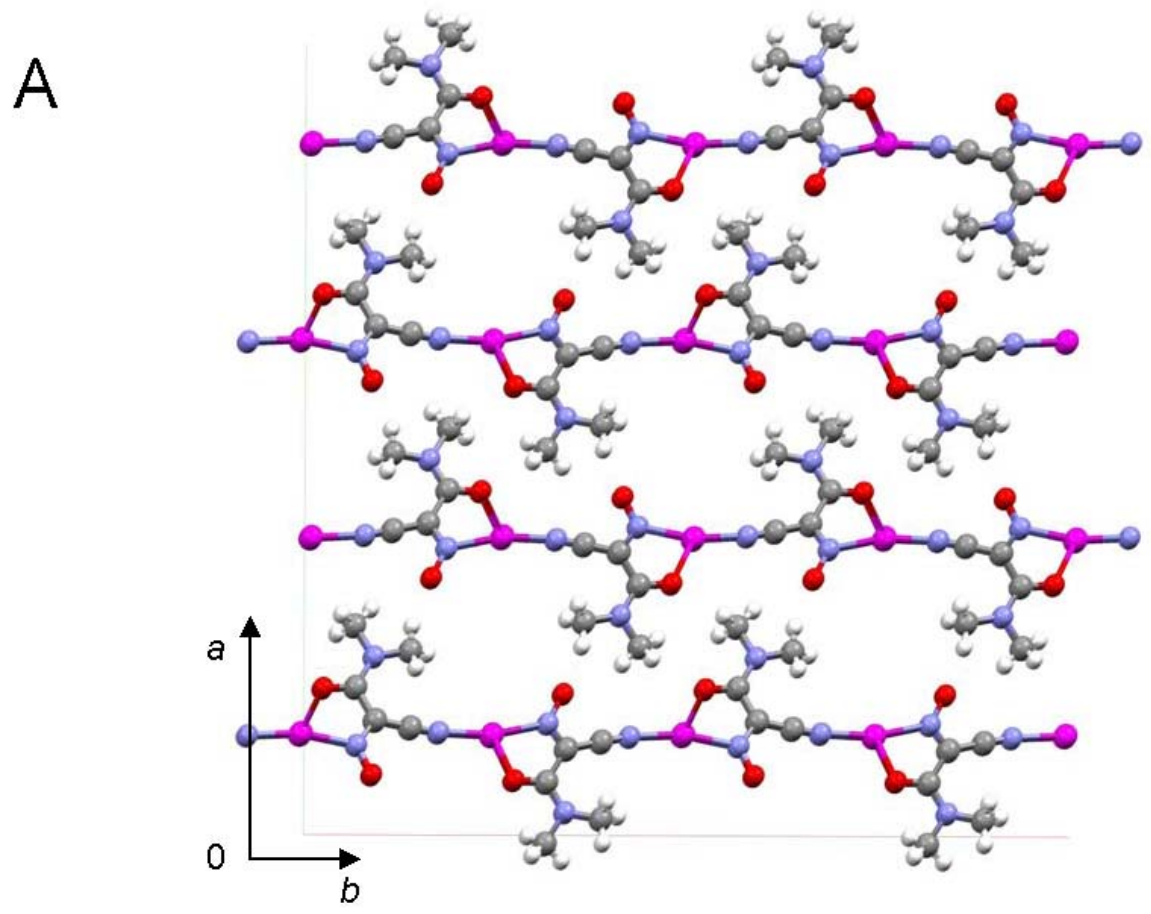


Figure 16. Cont.

B

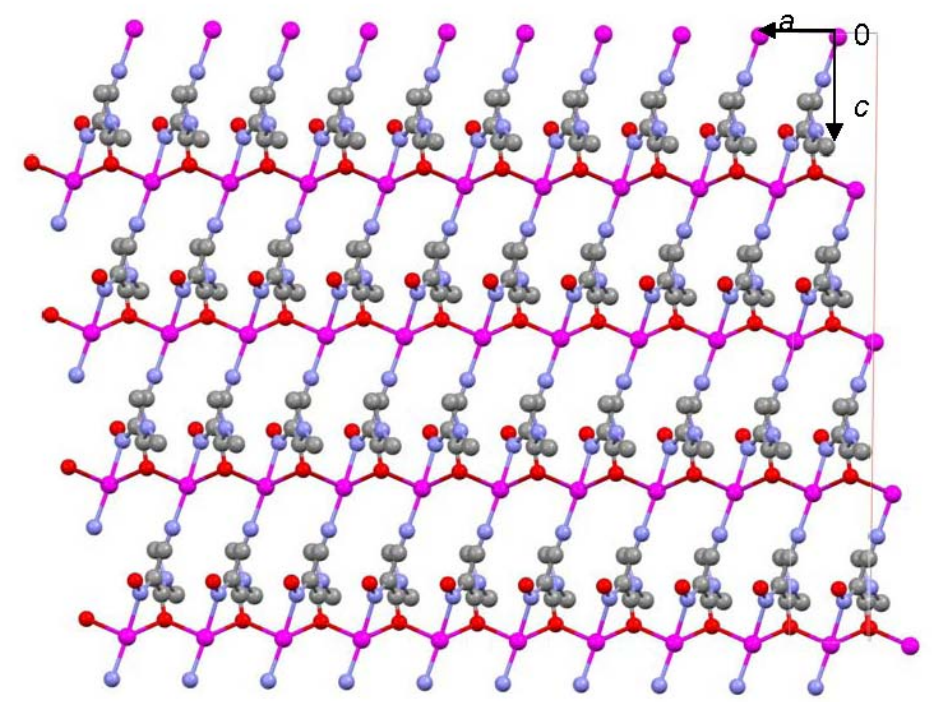

Figure 17. Organization of layered 2D structure of $\operatorname{Ag}(\mathrm{ECO})$ : view of two unit cells along $a$ showing polymeric motif (A), and two views along $b(\mathbf{B})$, and $a b$-diagonal of the unit cell $(\mathbf{C})$.

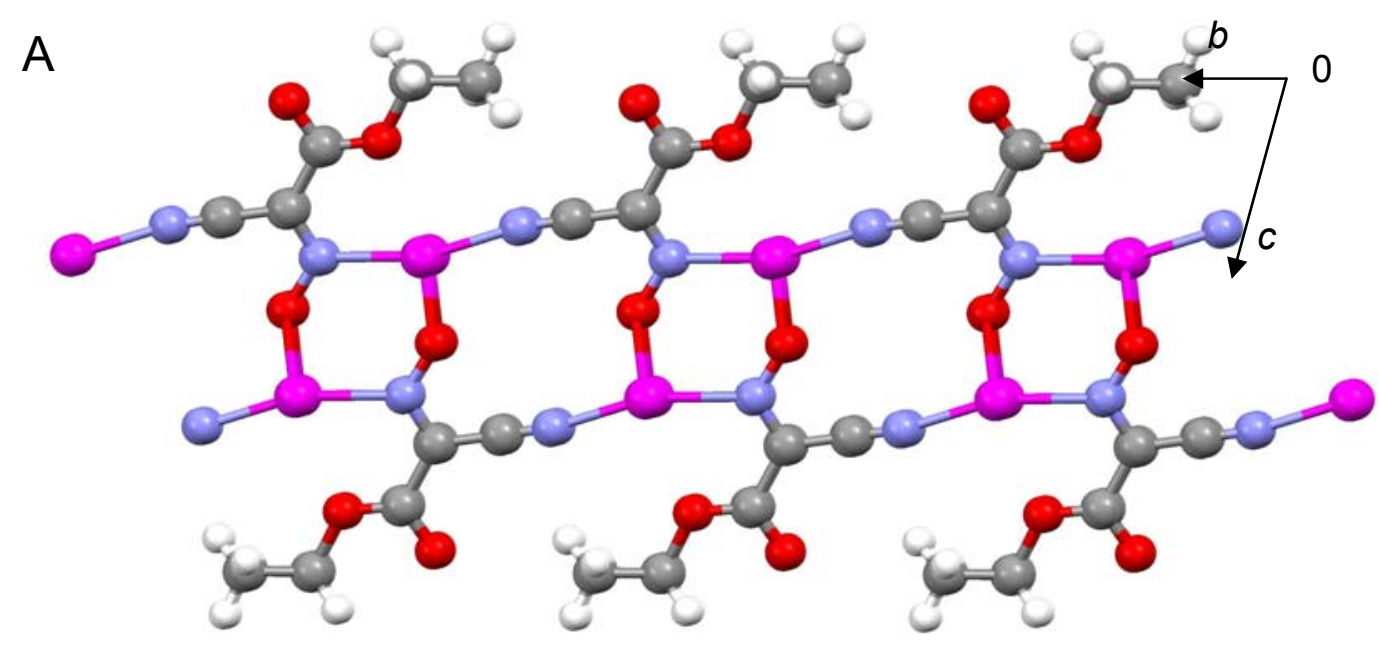

B
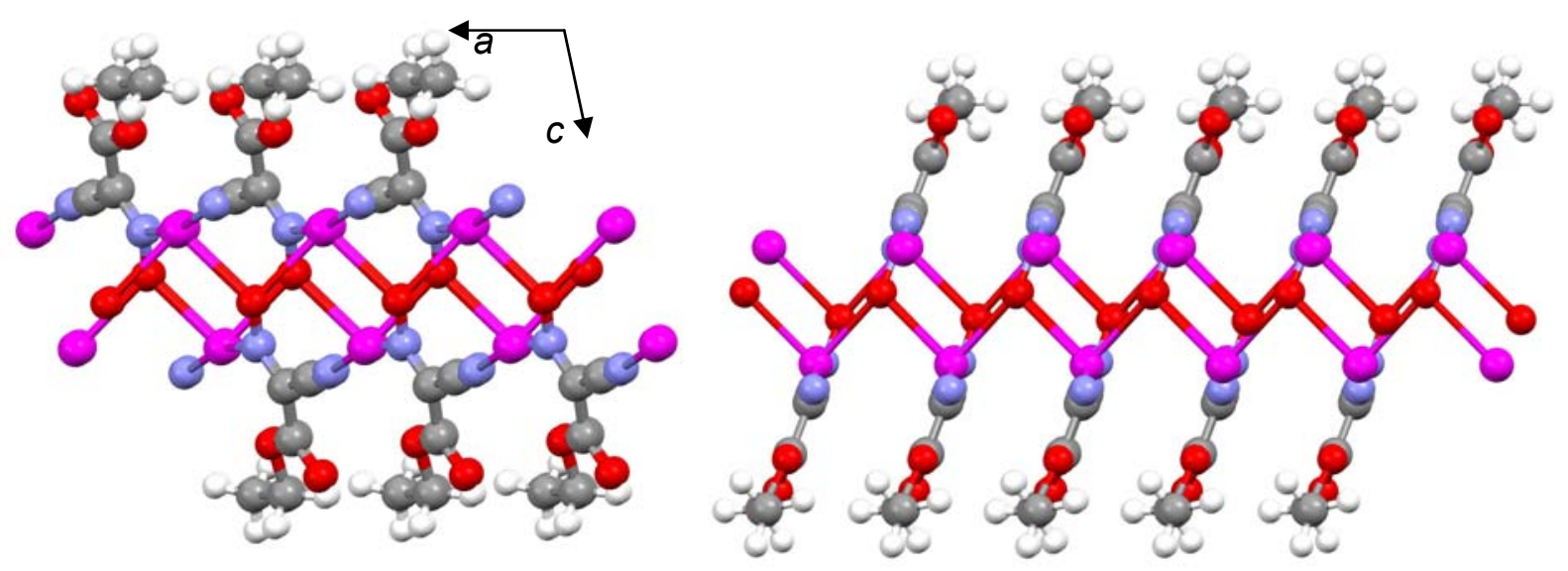
Figure 18. Organization of layered 2D structure of $\mathrm{Ag}(\mathrm{PiCO})$ : view of two unit cells along $a$ showing polymeric motif and inter-layer van-der-Waals interactions between t-butyl groups (A), and two views along $c$ direction (B).
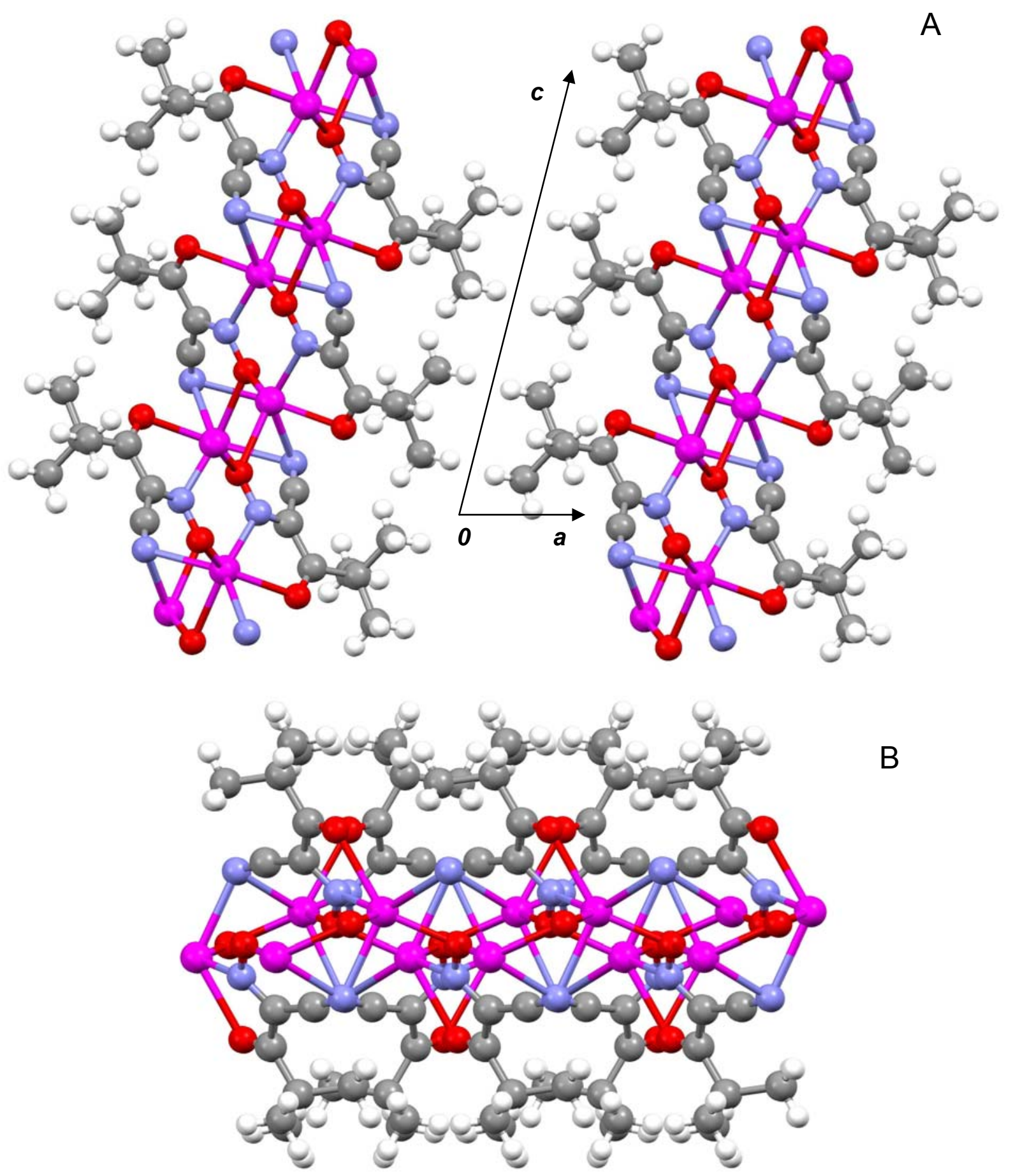

B

In summary, silver(I) cyanoximates showed much greater structural diversity than their thallium(I) analogs. The AgL exhibited very interesting structures with no two looking alike. Also, there is much more covalent character in Ag---L bonds than similar Tl---L bonds since they are significantly shorter than the sum of ionic radii between metal and participating donor atoms of nitrogen and oxygen (ESI 21). Namely this feature is the cause of a rather remarkable visible light insensitivity of silver(I) coordination polymers described here. Thus, based on available up-to-date crystal data for studied 
light-stable AgL, the visible light insensitive motif includes bridging nitroso-group (six out of six cases!) and metal to CN-group coordination (five out of six cases) as shown in Scheme 5. Therefore, an anion must act as at least tridentate bridging ligand and adopt the anti-configuration (ESI 2).

Scheme 5. The "visible light insensitive motif" in structures of light stable AgL.

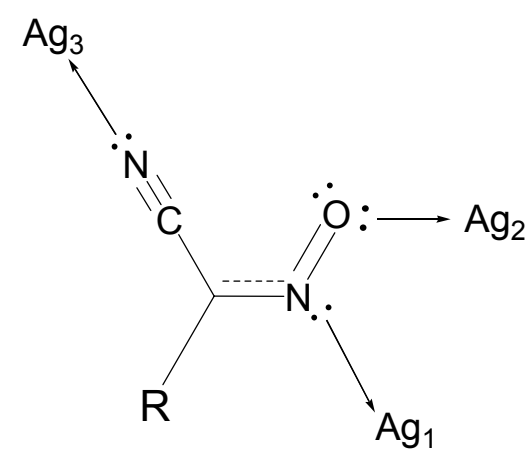

\subsection{Practicality of the Light-Stable Ag(I) Cyanoximates}

There are three areas of potential interest to these complexes: (1) battery-less, colorimetric area detectors of UV-, and, possibly, even gamma-radiation; (2) non electrical sensors for gases of industrial importance; (3) antimicrobial additives to light-curable adhesives employed during introduction of indwelling medical devices.

The first two fields of practical interest are dedicated to applications of $\mathrm{AgL}$ as sensors and new materials $[19,20]$ that are immensely convenient to handle and work with since they do not require dark rooms and special conditions. The latter must be normally obeyed during work with common light-sensitive silver(I) compounds. Despite being very stable towards visible light, solid powders of AgL being exposed to the UV-light develop contrast and sharp images (Figure 19; ESI 22). A detailed investigation of the irreversible color change and samples darkening revealed that it occurs only on the surface of solid samples with the rest of the bulk sample left intact [19-21]. Moreover, the degree of change depends on a dose of absorbed by the sample UV-radiation (ESI 23), which can be utilized in further development of non-electrical, colorimetric detectors of UV-radiation and, perhaps, even for the detection of higher energy photons such as gamma radiation. Thus, sensors containing visible light insensitive silver(I) cyanoximates can be used similarly to the $\mathrm{pH}$ paper indicator which changes color depending on acidity of solution, while solid AgL will change color depending on a dose of absorbed radiation (Figure 20). Proposed battery-less sensors can be made as self-adhesive strips that, for example, may be attached to the walls in premises where there is a UV-radiation and can work as area detectors. They can be used, for instance, in: (1) production sites with intensive welding (automobiles, other machines manufacturing, interior constructions/repairs); (2) electronic industry (printed circuit boards); (3) habitable space objects and labs. 
Figure 19. Images on the surface of solid powders of $\mathrm{AgL}$ developed after prolonged exposure to the short wavelength UV-radiation $(254 \mathrm{~nm})$; shown black cardboard masks and a coin for size comparison.
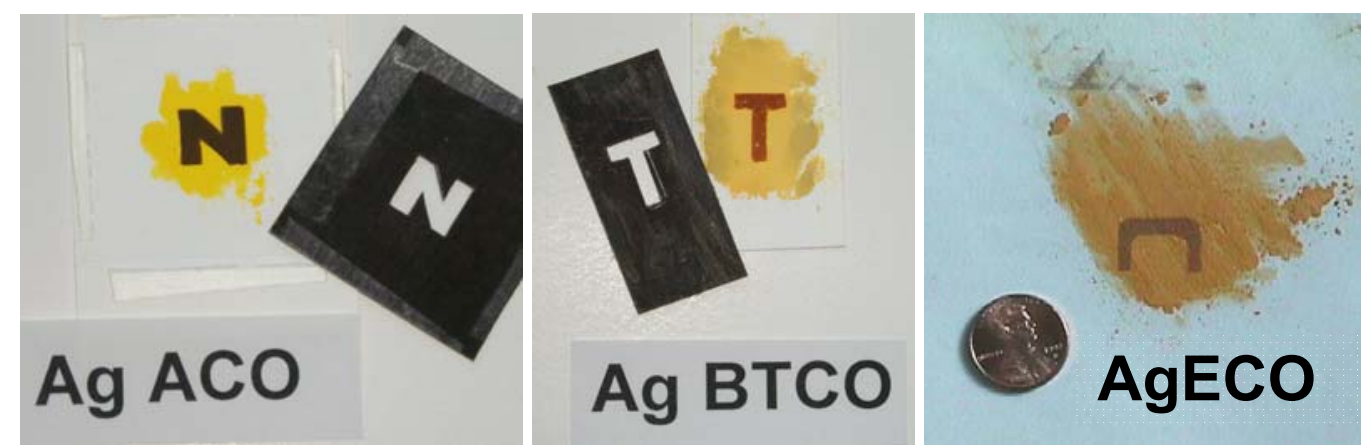

Figure 20. Practicality of color change upon exposure of $\operatorname{Ag}(\mathrm{I})$ cyanoximates to short-wavelength UV-radiation: potential for the battery-less colorimetric area detector for high-energy photons.

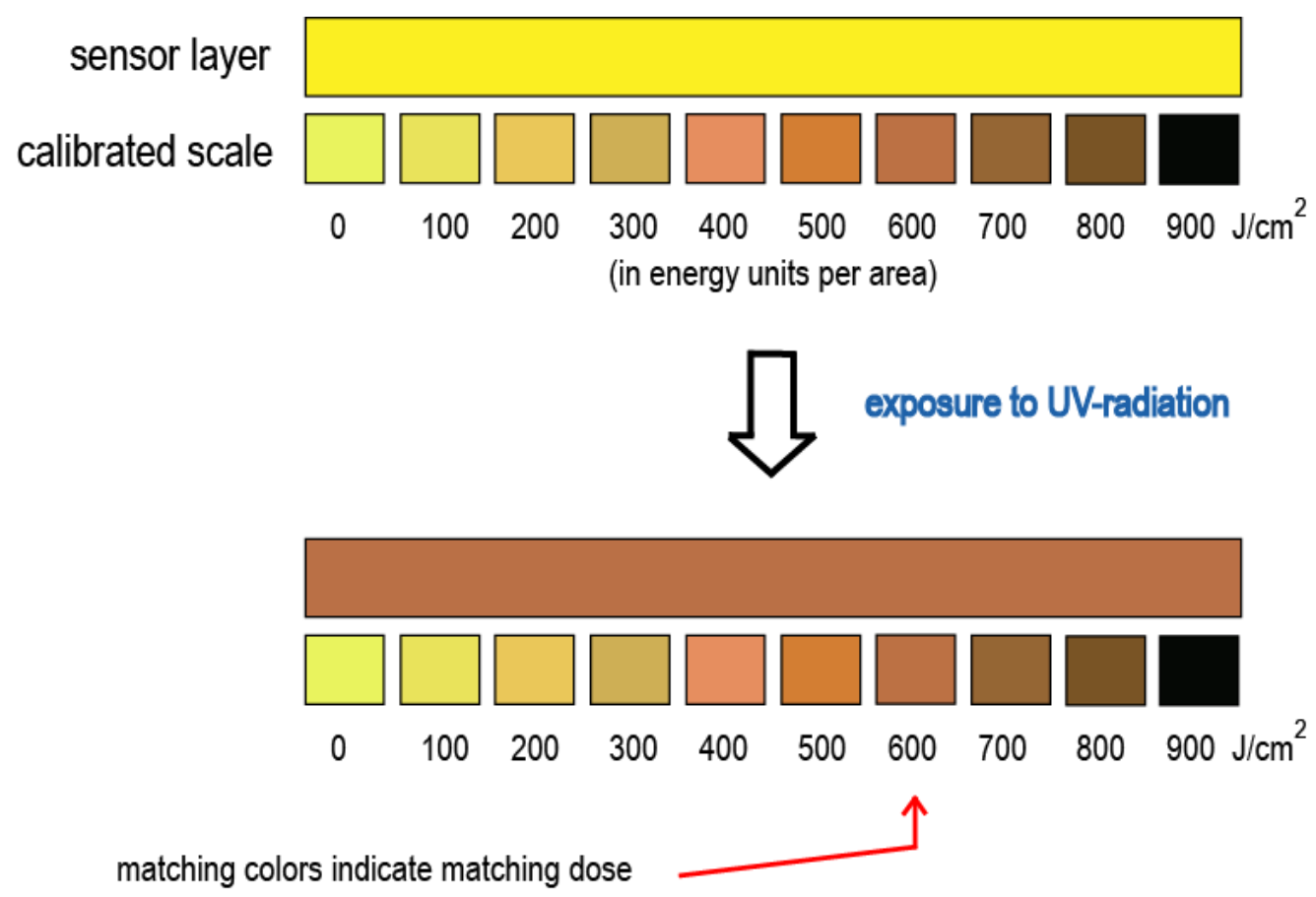

The darkening of studied AgL under intense and prolonged UV-irradiation is attributed to the photoreduction of $\mathrm{Ag}^{+}$to a very fine particles of metallic silver that readily forms colloid solutions in organic solvents such as DMF, pyridine and DMSO [21,51]. Because of the significant degree of covalence in bonds between the bridging ligand and the silver atom in complexes, synthesized and studied coordination polymers of silver(I) cyanoximates undergo photodecomposition by photons of much higher energy than visible light, which is a tentative explanation for the visible light insensitivity of AgL. 
Silver(I) cyanoximates were also found to exhibit decrease in their photoluminescence in the presence of several gases of industrial significance such as $\mathrm{H}_{2}, \mathrm{CO}, \mathrm{NO}, \mathrm{SO}_{2}, \mathrm{C}_{2} \mathrm{H}_{2}$ and $\mathrm{C}_{2} \mathrm{H}_{4}[19,20]$. Using specially designed gas cuvette (ESI 24) it was possible to investigate the emissive properties of two complexes: $\mathrm{Ag}(\mathrm{CCO})$ and $\mathrm{Ag}(\mathrm{ACO})$. All measurements were carried out within some time intervals, at room temperature, and at normal pressure of the above gases. Typical results presented in Figure 21 and indicate certain trend in observed emissions quench with acetylene, nitrous oxide and sulfur dioxide being electron rich and the most responsive molecules [19,20]. The most interesting feature of these coordination polymers is in their developed sensitization: the initial solid AgL are not visible light sensitive, but being exposed to these gases of industrial importance become sensitized and rapidly, within minutes, irreversibly change color and darken. We attribute this behavior to the formation of a complex with the gas molecules on the surface of studied solids (ESI 25). Hence, this interesting effect can be used in the development of non-electrical sensors for these gases, which are highly flammable $\left(\mathrm{H}_{2}, \mathrm{C}_{2} \mathrm{H}_{4}, \mathrm{C}_{2} \mathrm{H}_{2}\right)$ and make explosive mixtures with air, or represent health hazard being toxic $(\mathrm{NO}, \mathrm{CO})$ and irritant $\left(\mathrm{SO}_{2}\right)$. For example, one can envision such sensor that can be attached again as self-adhesive strips to the walls of premises such as compressor and transfer stations, or to flanges/pipes and regularly monitored either visually, or via an optoelectronic pair as shown in Figure 22. Visible light stable AgL will change color and darken only in the presence of these gases, which provide the opportunity to detect gas leaks. A similar approach has been commercialized for the carbon monoxide detection.

Figure 21. Changes in emission of solid sample of $\mathrm{Ag}(\mathrm{CCO})$ with time in the presence of acetylene (A), and time profile of photoluminescence of $\mathrm{Ag}(\mathrm{ACO})$ in presence of several gases of industrial importance (B). Asterisks indicate instrumental artifacts.
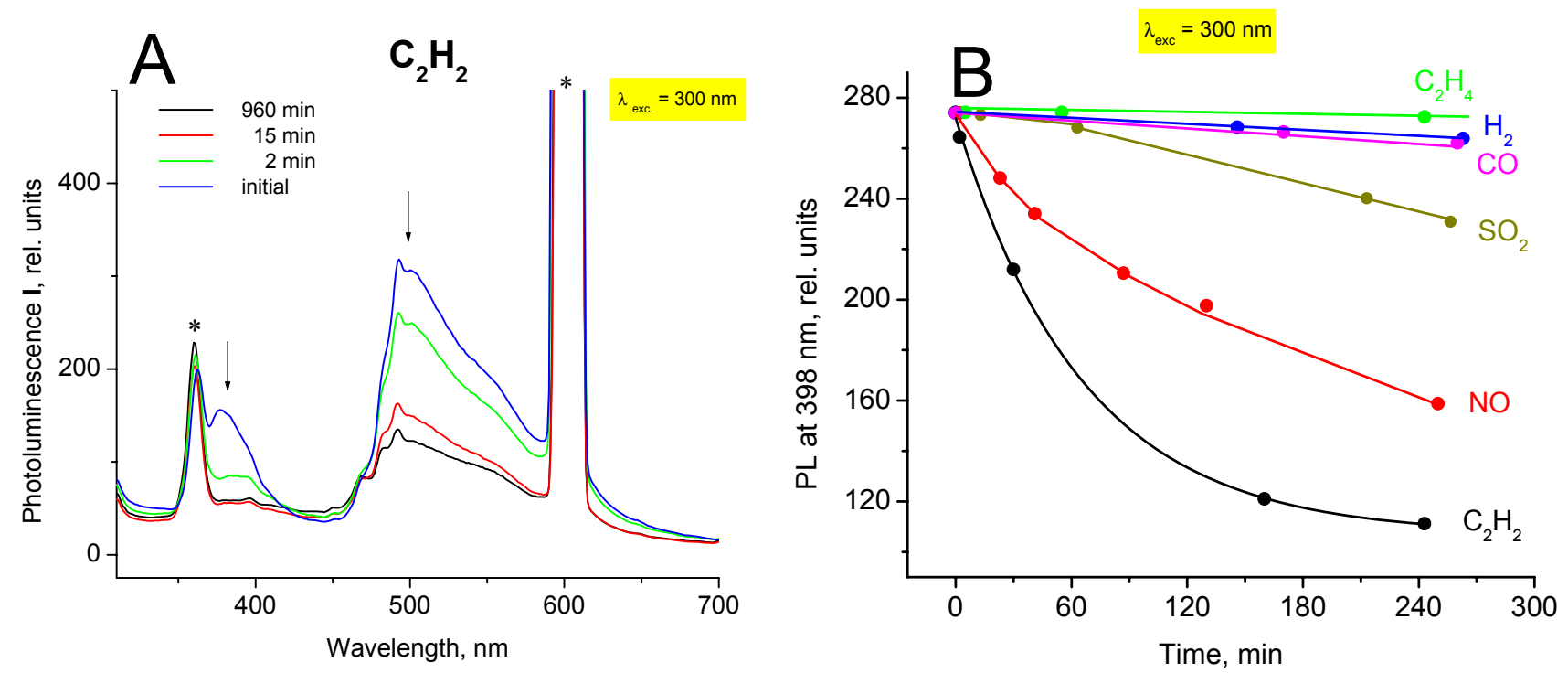
Figure 22. Schematic diagram of the optoelectronic pair working with silver(I) cyanoximates for quantitative detection of gases of industrial importance in closed, illumined premises. The light source could be a remote laser with remote detector measuring the intensity of reflected light from the surface of visible light stable AgL sensor (A). When the gas of interest is present, the surface of a sensor gets sensitized and darkens with little light reflected to the detector, which triggers the alarm circuit (B).
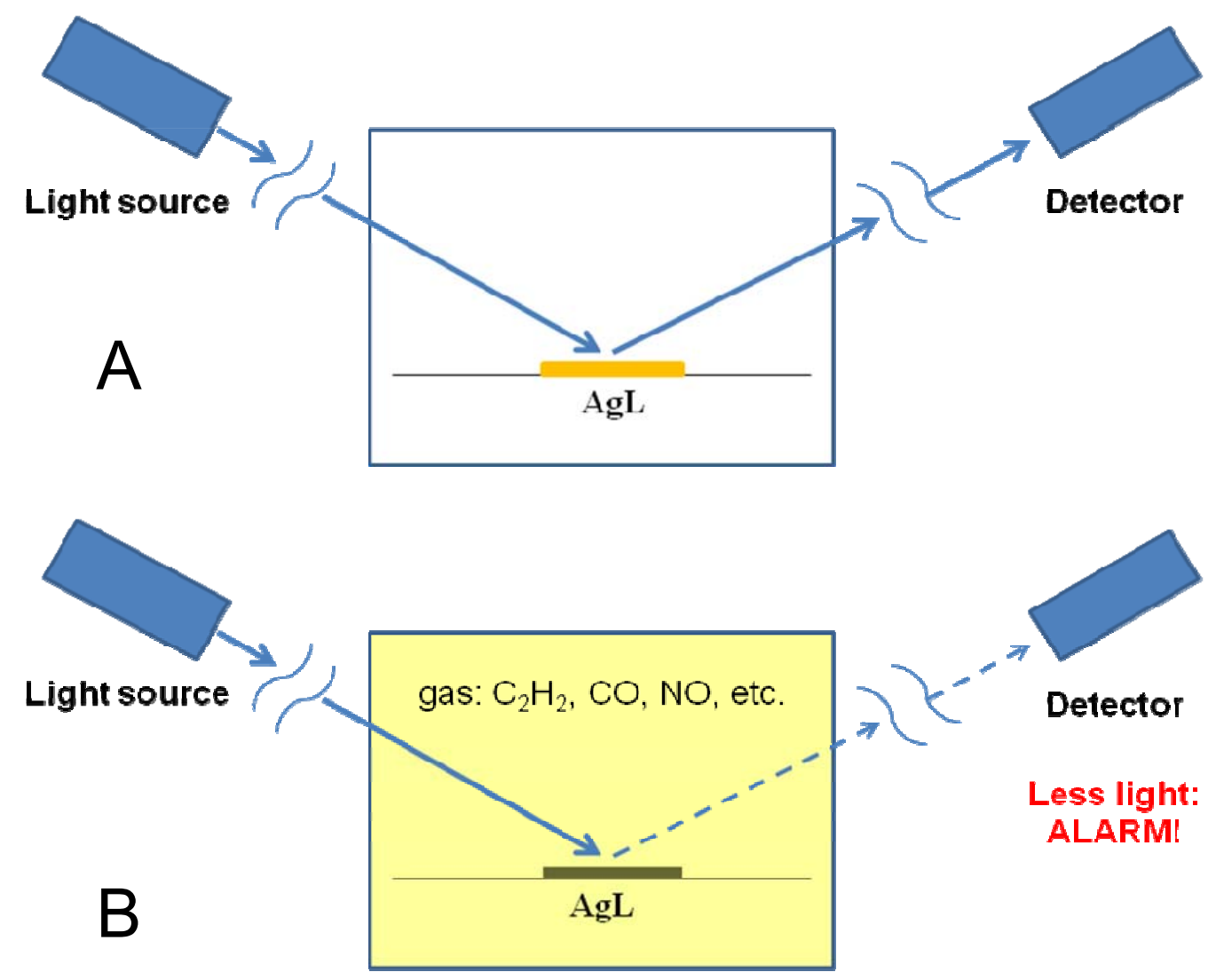

The third application of polymeric silver(I) cyanoximates belongs to a new inter-disciplinary area of research between coordination chemistry and biomedical sciences such as microbiology/infectious diseases, and the use of implants/prosthetic devices. In this context it is important to mention that the number of patients requiring an internal fixation device or artificial joint has grown rapidly. In the United States alone more than 4.4 million people have at least one internal fixation device and more than 1.3 million people have an artificial joint [55]. Bacterial infection induced by implant placement is a significant rising complication and is associated with considerable morbidity and costs [56]. Clinical practice has shown that systemic antibiotics are unable to provide effective treatment for implant-associated infections. At the present time, only a high dose of antibiotics applied locally at the bone-implant interface can prevent such bacterial infections. However, this prophylaxis causes a number of side effects, such as increased bacterial resistance to antibiotics, allergic reactions, and microbial flora depletion. Thus, it is often the best solution to remove the device, treat the infection and repeat surgical introduction of a new device. This kind of procedure is costly, both financially and psychologically, as well as time consuming. The development of new infection-preventing strategies and antibacterial agents in particular are a critical priority as artificial implant therapy rapidly increases in use. One of the interesting options is an introduction of the non-antibiotic antimicrobial substance, 
for example, into the glue used during introduction of indwelling medical devises, or provide the surface treatment of such devices to prevent pathogenic cell adhesion and biofilm formation. Silver has long been known to exhibit strong inhibitory and bactericidal effects as well as a broad spectrum of antibacterial properties [57]. Since ancient times, people have known that water can remain suitable for drinking for a long time if stored in silver jars. One of the applications of silver and its compounds is reduction of postoperative infections caused by implants. Thus, silver compounds were loaded into some implant materials such as bioglass [58] and bone cement [59]. It is reported that the incorporation of silver into implants is a most promising method in reducing the infection rate, while exhibiting low toxicity towards cells and tissues [60]. Silver incorporating biomaterials, therefore, have tremendous potential for advancing the safety of internal implant therapies in the health care industry [61-63]. With the exception of several publications [64-67], there were no systematic studies regarding light-, heat-, chemically stable, water insoluble silver(I) antimicrobial compounds targeting specific infections, and no oxime-based compounds were tested on that matter at all.

We have recently discovered that our polymeric silver(I) cyanoximates satisfy the aforementioned essential requirements for implant materials and additives as they are: (a) water insoluble, (b) chemically relatively inert and do not undergo further chemical transformations, (c) light stable to withstand curing with an intense $400 \mathrm{~nm}$ light for many minutes [19-21,51], (d) thermally stable up to $150{ }^{\circ} \mathrm{C}$ without decomposition, which is important property for materials/devices sterilization purposes. Synthesized AgL also exhibit antibacterial, but not cytotoxic, effect towards human cells and tissues. Thus, we performed in vitro studies of antimicrobial properties of ten synthesized light stable silver(I) cyanoximates both in solutions and in solid state. Gram-positive and gram-negative bacteria and yeasts, commonly isolated from patients suffering inplant-related infections, were employed in these investigations. The cultures included Escherichia coli, Pseudomonas aeruginosa, Klebsiella pneumoniae, Streptococcus mutans, Staphylococcus aureus, Mycobacterium fortuitum, Enterococcus hirae, Proteus sporidium. In addition, several multidrug-resistant bacterial strains isolated from patients with nosocomial infections Enterococcus faecium VRE (vancomycin-resistant), K. pneumoniae 244, Streprococcus pneumoniae PCI, P. aeruginosa, AMA, S. aureus (methicillin-resistant) were also included into the in vitro screenings [21]. The antimicrobial effect of solid silver(I) cyanoximates deposited as pressed $12 \mathrm{~mm}$ in diameter pellets was tested against 5 strains of microorganisms grown on agar plates. Figure 23 shows one example of growth inhibition experiments and demonstrated clear inhibition zones in $P$. aeruginosa growth in the presence of $\operatorname{Ag}(\mathrm{BOCO}), \operatorname{Ag}(\mathrm{CCO})$ and $\operatorname{Ag}(\mathrm{DCO})$ pellets. More complete and detailed quantitative data regarding these investigations was recently published [21].

In summary, described here light-stable silver(I) cyanoximates can be applied as antimicrobial additives to light-curable polymeric adhesives and composites used during introduction of indwelling medical devices, implants (ESI 26), and dental filling material. Presence of AgL will prevent infection from occurring keeping all other important properties of adhesives and composites intact. Results of our preliminary tests using conventional acrylate-based polymeric flowable dental composites and powdery samples of $\operatorname{Ag}(\mathrm{CCO})$ showed excellent miscibility and tolerance between them without any changes for the extended period of time (Figure 24; ESI 27). 
Figure 23. Zones of inhibition by $\mathrm{Ag}(\mathrm{PiCO}), \mathrm{Ag}(\mathrm{BCO})$ and $\operatorname{Ag}(\mathrm{BIMCO})$ pellets in $P$. aeruginosa growth on solid media. Photographs of the agar plate showing zones of inhibition: (A) top view, (B) bottom view.

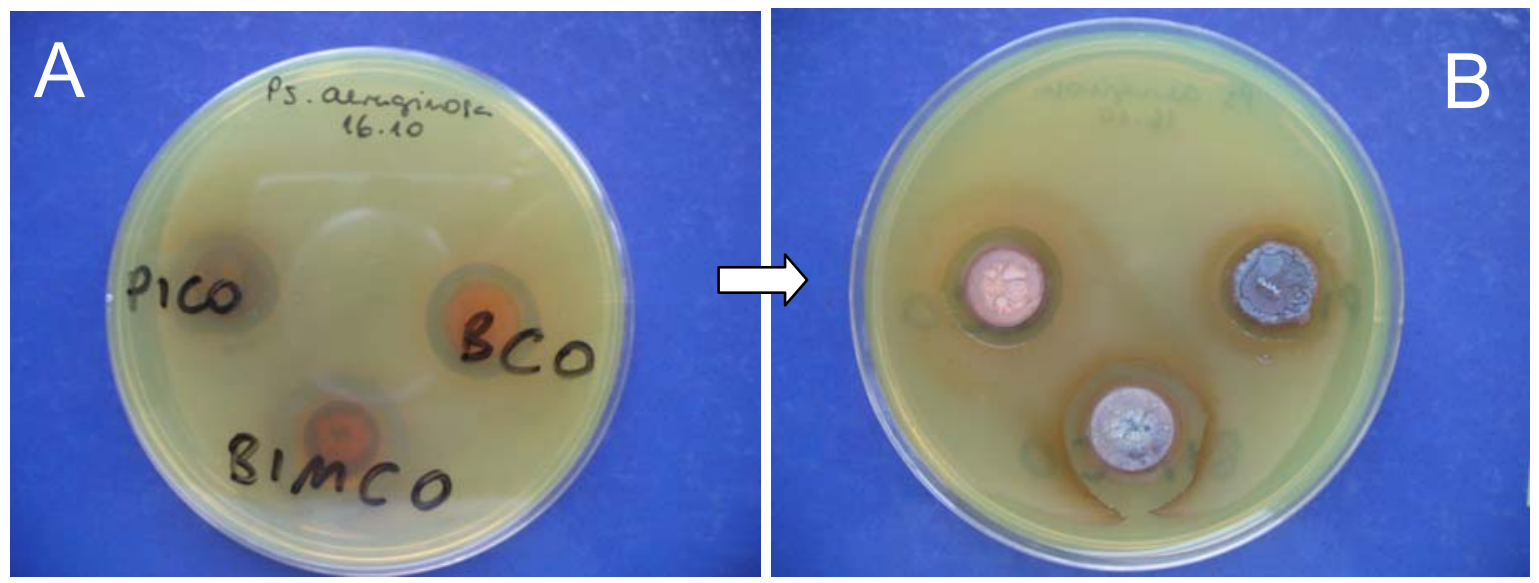

Figure 24. Microscope photographs $(\times 40)$ of solid samples of two different flowable dental composites that contain $\sim 10$ mass $\%$ of $\operatorname{Ag}(\mathrm{CCO})$. Different matrices required different time for solidifying by curing with $400 \mathrm{~nm}$ light from the LED source.

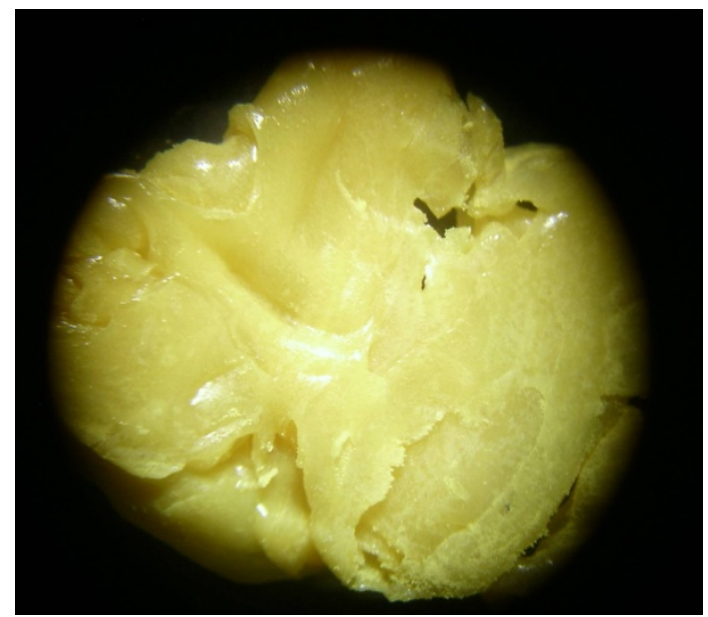

$40 \mathrm{~s}$

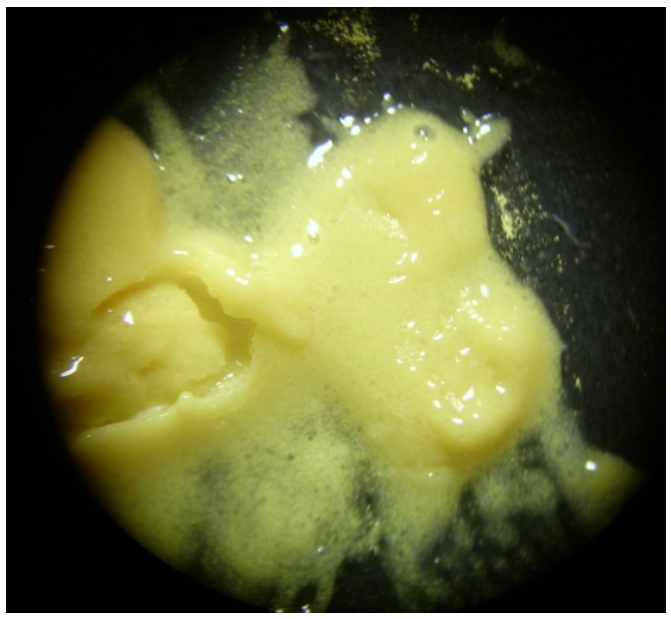

$140 \mathrm{~s}$

\section{Conclusions}

(1) High-yield methods of synthesis of a large series of cyanoximes, total 37 up-to-date, were developed using modified Meyer reaction. Also, a big group of monovalent thallium and silver cyanoximates of $\mathrm{ML}$ composition $(\mathrm{M}=\mathrm{Tl}, \mathrm{Ag} ; \mathrm{L}=$ cyanoxime anions) were prepared using simple procedures employing $\mathrm{Tl}_{2} \mathrm{CO}_{2}$ or $\mathrm{AgNO}_{3}$ in aqueous solutions. All metal compounds are thermally stable up to $\sim 160{ }^{\circ} \mathrm{C}$ and represent sparingly soluble in water crystalline materials. Synthesized complex compounds were characterized by the variety of spectroscopic methods and the X-ray analysis: 14 crystal structures of TIL and 6 structures of AgL complexes were determined. All obtained and studied complexes represent 2D and 3D coordination polymers in which cyanoxime anions act as bridging ligands of different denticity. 
(2) Thallium cyanoximates demonstrate very interesting structures in which the $6 \mathrm{~s}^{2}$ lone pair is stereoactive and affects (significantly distorts) the shape of coordination polyhedrons of the metal center in complexes. The most common structural motif found in these complexes is a 2D double-stranded "ladder-type" polymer. Some complexes demonstrate very short intermetallic separation of 3.66-3.74 $\AA$, which is very close to that in metallic thallium $(3.47 \AA)$, and be utilized in preparation of mixed valence $\mathrm{Tl}(\mathrm{I}) / \mathrm{Tl}(\mathrm{III})$ coordination polymers that exhibit electrical conductivity.

(3) Out of 37 synthesized AgL compounds 13 were found to be very resistant towards intense visible light for many years of exposure. However, within hours they develop irreversible and pronounced color change and darkening after exposure to short wavelength (254 nm) UV-radiation with absorbed doses up to $\sim 200 \mathrm{~J} / \mathrm{cm}^{2}$. This property can be utilized in further development of a battery-less, convenient area detectors of high energy photons such as UV-light and, possibly, X-ray and gamma radiation. Product of photodegradation of AgL is metallic silver, which in solutions aggregates into colloid suspensions of nano-size particles.

(4) The origin of light insensitivity of obtained silver(I) cyanoximates is in strong covalent bonding in the structures of 2D-coordination polymers formed.

(5) Synthesized visible light insensitive AgL complexes exhibit in the solid state photoluminescence quenching in the presence of several gases of industrial importance. They also demonstrate pronounced photosensitization and darken only after exposure to some of these gases, which opens the possibility for complexes' application as non-electrical, colorimetric sensors, or as active color changing components of an optoelectronic pair.

(6) Ten synthesized and studied silver(I) cyanoximates both in solutions and in solid state demonstrated pronounced antimicrobial activity against a number of bacterial species commonly associated with implant-related infections. Hence, complexes can be used as additives to light-curable acrylate polymeric composites used during the introduction of indwelling medical devices.

\section{Acknowledgment}

Financial support was provided by the Research Corporation Award CC6598 and MSU Graduate College. The help of Andrzej Gamian and Bogumila Szponar from the Institute of Immunology and Experimental Therapy of Polish Academy of Sciences in Wroclaw (Poland) with antimicrobial studies is greatfully acknowledged. The author is also very grateful to his students-Konstantin Domasevitch, Andriy Mokhir, Daniel Robertson, Leon Goeden, Garrett Glover, Daniela Marcano and Jeff Morton for their effort and dedication during work on this project, and to Alex Corbett for technical help. Help of Konstantin Domasevitch in making presentable pictures for some of the Tl-cyanoximates is very much acknowledged. Practical help of Sergey Lindeman (Marquette University, Milwaukee, WI) with successful solution of the crystal structure of a multidomain $\mathrm{Tl}(2 \mathrm{~F}-\mathrm{PhCO})$ specimen is greatly appreciated. 


\section{References}

1. Jones, L.F.; O’Dea, L.; Offerman, D.A.; Jensen, P.; Moubaraki, B.; Murray, K.S. Benzotriazole Based 1-D, 2-D and 3-D Metal Dicyanamide and Tricyanomethanide Coordination Networks. Polyhedron 2006, 25, 360-372.

2. Young, C.G. Mixed-Valence Compounds of the Early Transition Metals. Coord. Chem. Rev. 1989, 96, 89-251.

3. Maji, T.K.; Kitagawa, S. Chemistry of porous coordination polymers. Pure Appl. Chem. 2007, 79, 2155-2177.

4. Gerasimchuk, N.N.; Bowman-James, K. Mixed Donor Ligands. In Encyclopedia of Inorganic Chemistry; King, B., Ed.; John Wiley \& Sons: Oxford, UK, 1994; Volume 5, pp. 2254-2269.

5. Owen, T.; Grandjean, F.; Long, G.J.; Domasevitch, K.V.; Gerasimchuk, N. Synthesis and Characterization of Two Intensely Colored tris(benzoylcyanoxime)iron(II) Anionic Complexes. Inorg. Chem. 2008, 47, 8704-8713.

6. Maher, T.; Gerasimchuk, N.; Durham, P.; Domasevitch, K.V.; Wilking, J.; Mokhir, A. Tin(IV) Cyanoximates: Synthesis, Characterization and in vitro Cytotoxicity. Inorg. Chem. 2007, 46, 7268-7284.

7. Gerasimchuk, N., Dalley, N.K. Demetallation of Ni(II) Tetraazamacrocyclic Complex by Cyanoxime Resulting in the Formation of a Stereospecific Trinuclear Compound $\left[\mathrm{Na}\left(\mathrm{H}_{2} \mathrm{O}\right)_{6}\right]^{+}\left[\mathrm{NaNi}_{2} \mathrm{~L}_{6}\right]^{-}\left(\mathrm{L}=\mathrm{NC}-\mathrm{C}(\mathrm{NO})-\mathrm{C}(\mathrm{O}) \mathrm{NH}_{2}{ }^{-}\right)$. J. Coord. Chem. 2004, 57, 1431-1442.

8. Gerasimchuk, N.N.; Simonov, Y.A.; Dvorkin, A.A. ; Rebrova, O.N. Synthesis, IR Spectra and Structure of Lead(II) Complex with Amide-Cyanoximate-ion $\mathrm{ONC}(\mathrm{CN}) \mathrm{C}(\mathrm{O}) \mathrm{NH}_{2}{ }^{-}$. Russ. J. Inorg. Chem. 1993, 38, 247-252.

9. Gerasimchuk, N.N.; Skopenko, V.V.; Ponomareva, V.V.; Domasevitch, K.V. The Benzoylcyanoxime-Ion and Its Properties as a Ligand. Russ. J. Inorg. Chem. 1993, 38, 964-970.

10. Eddings, D.; Barnes, C.; Gerasimchuk, N.; Durham, P.; Domasevich, K. First Bivalent Palladium and Platinum Cyanoximates: Synthesis, Characterization and Biological Activity. Inorg. Chem. 2004, 43, 3894-3909.

11. Charlier, H.; Gerasimchuk, N. Cyanoxime Inhibitors of Carbonyl Reductase and methods of Using Said Inhibitors in Tratments Involving Antracyclines. U.S. Patent 7,727,967 B2, 1 June 2010.

12. Ilkun, O.T.; Archibald, S.; Barnes, C.L.; Gerasimchuk, N.; Biagioni, R.; Silchenko, S.; Gerasimchuk, O.A.; Nemykin, V. Benz(2-heteroaryl)cyanoximes and Their Tl(I) Complexes: New Room Temperature Blue Emitters. J. Chem. Soc. Dalton Trans. 2008, doi: 10.1039/B803846E.

13. Gerasimchuk, N.; Barnes, C.L.; Boaz, D. Preparation, Spectroscopic and Structural Characterization of the First Co(III) Cyanoxime Complex: Two Polymorphs of fac-, tris-(benzoylcyanoximato)cobalt(III), Co(BCO) 3 . J. Coord. Chem. 2010, 63, 943-953.

14. CRC Handbook of Chemistry and Physics, 56th ed.; CRC Press, Chemical Rubber Co.: Boca Raton, FL, USA, 1974.

15. Dean, J.A. Lange's Handbook of Chemistry, 14th ed.; McGraw-Hill: New York, NY, USA, 1992.

16. Burmeister, J.L. Ambidentate Ligands, the Schizophrenics of Coordination Chemistry. Coord. Chem. Rev. 1990, 105, 77-133. 
17. Golub, A. M.; Kohler, H.; Skopenko, V.V. Chemistry of Pseudohalides; Clark, R.J.H., Ed.; Topics in Inorganic and General Chemistry, Monograph 21; Elsevier: Amsterdam, The Netherlands, 1986.

18. Das, D.; Laskar, I.R.; Ghosh, A.; Mondal, A.; Okamoto, K.-I.; Chaudhuri, N.R. First Structural Characterisation of Nitro-Nitrito Linkage Isomers of Nickel(II): Synthesis and Single Crystal Structures of $\left[\mathrm{NiL}_{2}\left(\mathrm{NO}_{2}\right)_{2}\right]$ and $\left[\mathrm{NiL}_{2}(\mathrm{ONO})_{2}\right]$ [L $=1$-(2-aminoethyl)piperidine]. J. Chem. Soc. Dalton Trans. 1998, doi: 10.1039/A806858E.

19. Glower, G.; Gerasimchuk, N.; Biagioni, R.; Domasevitch, K.V. Monovalent K, Cs, Tl and Ag Nitrosodicyanmethanides: Completely Different 3D Networks with Useful Properties of Luminescent Materials and Nonelectric Sensors for Gases. Inorg. Chem. 2009, 48, 2371-2382.

20. Gerasimchuk, N.; Esaulenko, A.N.; Dalley, K.N.; Moore, C. 2-Cyano-2-Isonitroso Acetamide and Its Ag(I) Complexes. Silver(I) Cyanoximate as a Non-Electric Gas Sensor. J. Chem. Soc. Dalton Trans. 2010, 39, 749-764.

21. Gerasimchuk, N.; Gamian, A.; Glover, G.; Szponar, B. Light Insensitive Silver(I) Cyanoximates as Antimicrobial Agents for Indwelling Medical Devices. Inorg. Chem. 2010, 49, 9863-9874.

22. Robertson, D.; Cannon, J.; Gerasimchuk, N. Double-Stranded Metal-Organic Networks for One-Dimensional Mixed Valence Coordination Polymers. Inorg. Chem. 2005, 44, 8326-8342.

23. Terril, R.H., Murray, R.W. Electron Hopping Transport in Electrochemically Active, Molecular Mixed Valent Materials. In Molecular Electronics; Ratner, J.M., Ed.; Blackwell Science: Hoboken, NJ, USA, 1997; pp. 215-239.

24. Gill, M.L.; Strobel, S.A.; Loria, J.P. ${ }^{205} \mathrm{Tl}$ NMR Methods for the Characterization of Monovalent Cation Binding to Nucleic Acids. J. Am. Chem. Soc. 2005, 127, 16723-16732.

25. Cotton, A.F.; Wilkinson, G.; Murillo, C.A.; Bohmann, M. Advanced Inorganic Chemistry, 6th Ed., John Wiley \& Sons: Hoboken, NJ, USA, 1999.

26. Pearson, R.G. Hard and Soft Acids and Bases; Dowden, Hutchison \& Ross, Inc.: Stroudsberg, PA, USA, 1973.

27. A comprehensive source of information about properties of elements. Available online: http://webelements.com (accessed on 6 June 2011).

28. Gillespie, R.J. Fifty Years of the VSEPR Model. Coord. Chem. Rev. 2008, 252, 1315-1327.

29. Miessler, G.L.; Tarr, D.A. Inorganic Chemistry, 3rd ed.; Prentice Hall: Englewood Cliffs, NJ, USA, 2004.

30. Dennehy, M.; Quinzani, O.V.; Burrow, R.A. Poly[( $\mu_{3}-1,1-$ dioxo-1,2-benzoisothiazole-3 thiolato- $\left.\kappa^{3} \mathrm{~N}: \mathrm{S}^{3}: \mathrm{S}^{3}\right)$ silver(I)]. Acta Cryst. 2007, C63, m395-m397.

31. Glaser, J. Advances in Inorganic Chemistry; Sykes, A.J., Ed.; Academic Press: San Diego, CA, USA, 1995; Volume 43, p. 1.

32. Emsley, J. The Elements; Clarendon Press: Oxford, UK, 1991.

33. Goeden, L.; Gerasimchuk, N.; Durham, P.; Barnes, C.; Cannon, J.F. Synthesis and Characterization of the First Disubstituted Arylcyanoximes and their Several Metal Complexes. Inorg. Chim. Acta 2008, 361, 1983-2001.

34. Domasevitch, K.V.; Mokhir, A.A.; Rusanov, E.B. Nitroso Group Coordination in Thallium(I) Oximate Complexes with 18-Crown-6. J. Coord. Chem. 1995, 36, 15-22. 
35. Gerasimchuk, N.N.; Tchernega, A.N.; Kapshuk, A.A. Synthesis, IR Spectra and Structure of Complex $\mathrm{Tl}(\mathrm{I})$ with Carbamoylcyanoxime $\mathrm{HONC}(\mathrm{CN}) \mathrm{C}(\mathrm{O}) \mathrm{NH}_{2}$. Russ. J. Inorg. Chem. 1993, 38, 1530-1534.

36. Domasevitch, K.V.; Skopenko, V.V.; Sieler, J. Synthesis and Crystal Structure of a Thallium(I) Hydrogen Benzothiazolylcyanximate Complex with 18-Crown-6: the Thallium Atom is in the Center of the Crown Ether Cavity. Inorg. Chim. Acta 1995, 249, 151-155.

37. Gordon, A.J., Ford, R.A. The Chemist Companion (Handbook); John Wiley \& Sons: New York, NY, USA, 1972; p. 304

38. Lide, D.R. Handbook of Chemistry and Physics, 81st ed.; CRC Press: Boca Raton, FL, USA, 2000.

39. Harrowfield, J.M.; Sharma, R.P.; Shand, T.M.; Skelton, B.W.; White, A.H. Structural Systematics of 2/4-Nitrophenoxide Complexes of Closed-Shell Metal Ions. 2-Nitrophenoxides of Group 1. Austr. J. Chem. 1998, doi: 10.1071/C97098.

40. Harrowfield, J. M.; Sharma, R. P.; Skelton, B. W.; White, A. H. Structural Systematics of 2/4Nitrophenoxide Complexes of Closed-Shell Metal Ions. III 2/4-Nitrophenoxides of Univalent Heavy Metals. Aust. J. Chem. 1998, 51, doi: 10.1071/C97098.

41. Pospisil, J.; Jess, I.; Näther, C.; Necas, M.; Taborsky, P. Luminescence Properties of "Double-Stranded Staircase" Copper(I) Halide Coordination Polymers with N-Containing Ligands. New J. Chem. 2011, 35, 861-864.

42. Kromp, T.; Sheldrick, W.S.; Näther, C. Network Motifs and Thermal Properties of Copper(I) Halide and Pseudohalide Coordination Polymers with 1, 7- and 4, 7-Phenanthroline. Zeit. Anorg. Allg. Chemi. 2003, 629, 45-54.

43. Blake, A.J.; Brooks, N.R.; Champness, N.R.; Hanton, L.H.; Hubberstey, P.; Schroder, M. Copper(1) Halide Supramolecular Networks Linked by N-Heterocyclic Donor Bridging Ligands. Pure Appl. Chem. 1998, 70, 2351-2357.

44. Shiotsuka, M.; Tanamachi, T.; Urakawa, T.; Munakata, M.; Matsuda, Y. Structure of Halogenophosphorincopper(I) Complexes in Solid State and Solution: Study with X-Ray Crystallography and CP/MAS- ${ }^{31} \mathrm{P}\left\{{ }^{1} \mathrm{H}\right\}$-NMR Spectroscopy. J. Supramol. Chem. 2002, 2, 211-217.

45. Day, P. Mixed-Valence Compounds. Proc. NATO ASI Ser C 1980, 58, 3-27.

46. Fackler, J.P. Mixed Valence Compounds. Encyclopedia of Inorganic Chemistry; John Wiley \& Sons: Oxford, UK, 1994; Volume 5, pp. 2270-2281.

47. Bardeen, J.; Cooper, L.N.; Schrieffer, J.R. Theory of superconductivity. Phys. Rev. 1957, 108, 1175-1204.

48. Khoshtariya, D.E.; Dolidze, T.D.; Zusman, L.D.; Lindberg, G.; Glaser, D. Two-Electron Transfer for $\mathrm{Tl}(\mathrm{aq})^{3+} / \mathrm{Tl}(\mathrm{aq})^{+}$Revisited. Common Virtual $\left[\mathrm{Tl}^{\mathrm{II}}-\mathrm{Tl}^{\mathrm{II}}\right]^{4+}$ Intermediate for Homogeneous (Superexchange) and Electrode (Sequential) Mechanisms. Inorg. Chem. 2002, 41, 1728-1738.

49. Tsirlina, G.A.; Petrii, O.A. Electrosynthesis and Electrochemical Behavior of Unusual Solid Thallium-Based Phases: Thallium Peroxide, Thallium(I)-Thallium(III) Mixed Oxide, Thallium Cuprate, and Thallium Oxyfluoride. J. Electroanal. Chem. 1996, 401, 33-43. 
50. Ponomareva, V.V.; Dalley, N.K.; Xiaolan Kou, Gerasimchuk, N.N.; Domasevich, K.V. Synthesis, Spectra and Crystal Structures of Complexes Including Ambidentate Benzoylcyanoxime Anion $\mathrm{C}_{6} \mathrm{H}_{5} \mathrm{C}(\mathrm{O})-\mathrm{C}(\mathrm{NO}) \mathrm{CN}^{-}$. J. Chem. Soc. Dalton Trans. 1996, doi: 10.1039/DT9960002351.

51. Morton, J. Further Investigations of Silver(I) Cyanoximates. M.Sc. Thesis, Missouri State University, Springfield, MO, USA, December 2010.

52. Domasevitch,K.V.; Petkova, E.G.; Nazarenko, A.Y.; Ponomareva, V.V.; Sieler, J.; Dalley, N.K.; Rusanov, E.B. Antimony as a Donor Atom in Silver Coordination Chemistry: Synthesis, IR Spectra and Structure of the Silver(I) Cyanoximate Complexes with triphenylstibine and Triphenylphosphine Model Compounds. Z. Naturforsch. 1999, 54b, 904-910.

53. Laguna, A.; Fernandez, E.J.; Lopez-de-Luzuriaga, J.M. Aurophilic Interactions. In Encyclopedia of Supramolecular Chemistry; Taylor \& Fransis: London, UK, 2004.

54. Skopenko, V.V.; Ponomareva, V.V.; Simonov, Y.A.; Domasevitch, K.V.; Dvorkin, A.A. Coordination Compounds of Thallium(I) and Silver(I) with Benzoylcyanoxime-Anion. Russ. J. Inorg. Chem. 1994, 39, 1332-1339.

55. Praemer, A.; Furner, S.; Rice, D.P.; Kelsey, J.L. Musculoskeletal Conditions in the United States; American Academy of Orthopaedic Surgeons: Park Ridge, IL, USA, 1992; pp. 27-41.

56. Chen, W.; Oh, S.; Ong, A.P.; Oh, N.; Liu, Y.; Courtney, H.S.; Appleford, M.; Ong, J.L. Antibacterial and Osteogenic Properties of Silver-Containing Hydroxyapatite Coatings Produced Using a Sol Gel Process. J. Biomed. Mater. Res. 2007, 82, 899-906.

57. Klasen, H.J. A Historical Review of the Use of Silver in the Treatment of Burns. II. Renewed Interest for Silver. Burns 2000, 26, 131-138.

58. Kawashita, M.; Tsuneyama, S.; Miyaji, F.; Kokubo, T.; Kozuka, H.; Yamamoto, K. Antibacterial Silver-Containing Silica Glass Prepared by Sol-Gel Method. Biomaterials 2000, 21, 393-398.

59. Alt, V.; Bechert, T.; Steinrucke, P.; Wagener, M.; Seidel, P.; Dingeldein, E.; Domann, E.; Schnettler, R. An in vitro Assessment of the Antibacterial Properties and Cytotoxicity of Nanoparticulate Silver Bone Cement. Biomaterials 2004, 25, 4383-4391.

60. Toshikazu, T. Antimicrobial Agent Composed of Silica-Gel with Silver Complex. Inorg. Mater. 1999, 6, 505-511.

61. Rujitanaroj, P.; Pimpha, N.; Supaphol, P. Wound Dressing Materials with Antibacterial Activity from Electrospun Gelatin Fiber Mats Containing Silver Nanoparticles. Polymer 2008, 49, 4723-4732.

62. Santoro, C.M.; Ducsherer, N.L.; Grainger, D.W. Minimal in vitro Antimicrobial Efficacy and Ocular Cell Toxicity from Nanoparticles. Nanobiotechnology 2007, 3, p. 55-65.

63. Valappil, S.P.; Pickup, D.M.; Carroll, D.L.; Hope, C.K.; Pratten, J.; Newport, R.J.; Smith, M.E.; Wilson, M.; Knowles, J.C. Effect of Silver Content on the Structure and Antibacterial Activity of Silver-Doped Phosphate-Based Glasses. Antimicr. Agents Chemother. 2007, 51, 4453-4461.

64. Fromm, K.M.; Brunetto, P.; Vig Slenters, T. Nanostructured Implant Surface Coating with Antimicrobial Properties. In Proceedings of the 237th ACS National Meeting, Salt Lake City, UT, USA, 22-26 March 2009; COLL-347.

65. Fromm, K.M. Silver(I) Coordination Polymers. In Proceedings of the ICCC-37, Oral Abstracts Book; Cape Town, South Africa, 13-18 August 2006. 
66. Slenters, T.V.; Hauser-Gerspach, I.; Daniels, A.U.; Fromm, K.M. Silver Coordination Compounds as Light-Stable, Nano-Structured and Anti-Bacterial Coatings for Dental Implant and Restorative Materials. J. Mater. Chem. 2008, 18, 5359-5362.

67. Kasuga, N.C.; Sato, M.; Amano, A.; Hara, A.; Tsuruta, S.; Sugie, A.; Nomiya, K. Light-Stable and Antimicrobial Active Silver(I) Complexes Composed of Triphenylphosphine and Amino Acid ligands: Synthesis, Crystal Structure, and Antimicrobial Activity of Silver(I) Complexes Constructed with Hard and Soft Donor Atoms $\left\{\left[\mathrm{Ag}(\mathrm{L})\left(\mathrm{PPh}_{3}\right)\right]_{2}\right\}$ with $\mathrm{L}=\alpha$-ala- or asn- and $\mathrm{n}=1$ or 2). Inorg. Chim. Acta. 2008, 361, 267-1273.

68. Gerasimchuk, N.N.; Domasevitch, K.V.; Kapshuk, A.A.; Tchernega, A.N. Coordination Compounds of N,N-Dimethylthioamidocyanoxime. Russ. J. Inorg. Chem. 1993, 38, 1718-1722.

69. Gerasimchuk, N.N.; Nagy, L.; Schmidt, H.-G.; Noltemeyer, M.; Bohra, R.; Roesky, H.W. Preparation, IR and X-Ray Crystal Structure Studies of Tl(I)-2-Pyridilcyanoxime Complex. Z. Naturforsch. 1992, 47b, 1741-1745.

70. Marcano, D. Pyridylcyanoximes and Their Metal Complexes. M.Sc. Thesis, Missouri State University, Springfield, MO, USA, December 2007.

71. Domasevitch, K.V. Structure of Thallium(I) Complex with Pivaloylcyanformaldoxime. The IR-Spectroscopic criterion of the NO Group Coordination. Russ. J. Gen. Chem. 1997, 67, 1937-1943.

72. Robertson, D. Thallium(I) Coordination Polymers Based on Monosubstituted Arylcyanoximes. M.Sc. Thesis, Missouri State University, Springfield, MO, USA, December 2006.

73. Domasevitch, K.V.; Skopenko, V.V.; Mokhir, A.A. Synthesis and Structure of the Thallium(I) Complex with 2-(4-methylthiazolyl)-cyanoxime. Russ. J. Inorg. Chem. 1995, 40, 781-786.

(C) 2011 by the authors; licensee MDPI, Basel, Switzerland. This article is an open access article distributed under the terms and conditions of the Creative Commons Attribution license http://creativecommons.org/licenses/by/3.0/). 